\title{
Eukaryotic inhibitors or activators elicit responses to chemosensory compounds by ruminal isotrichid and entodiniomorphid protozoa
}

\author{
H. L. Diaz, ${ }^{1}$ K. N. Barr, ${ }^{2}$ K. R. Godden, ${ }^{2}$ J. E. Plank, I. Zapata, A. N. Schappacher, M. P. Wick, and J. L. Firkins ${ }^{3}$ \\ Department of Animal Sciences, The Ohio State University, Columbus 43210
}

\begin{abstract}
Our objectives were to evaluate potential signaling pathways regulating rumen protozoal chemotaxis using eukaryotic inhibitors potentially coordinated with phagocytosis as assessed by fluorescent bead uptake kinetics. Wortmannin (inhibitor of phosphoinositide 3-kinase), insulin, genistein (purported inhibitor of a receptor tyrosine kinase), U73122 (inhibitor of phospholipase $\mathrm{C}$ ), and sodium nitroprusside (Snp, nitric oxide generator, activating protein kinase $\mathrm{G}$ ) were preincubated with mixed ruminal protozoa for $3 \mathrm{~h}$ before assessing uptake of fluorescent beads and chemosensory behavior to glucose, peptides, and their combination; peptides were also combined with guanosine triphosphate (GTP; a chemorepellent). Entodiniomorphids were chemoattracted to both glucose and peptides, but chemoattraction to glucose was increased by Snp and wortmannin without effect on chemoattraction to peptides. Rate of fluorescent bead uptake by an Entodinium caudatum culture decreased when beads were added simultaneously with feeding and incubated with wortmannin (statistical interaction). Wortmannin also decreased the proportion of mixed entodiniomorphids consuming beads. Isotrichid protozoa exhibited greater chemotaxis to glucose but, compared with entodiniomorphids, were chemorepelled to peptides. Wortmannin increased chemotaxis by entodiniomorphids but decreased chemotaxis to glucose by isotrichids. Motility assays documented that Snp and wortmannin decreased net swimming speed (distance among 2 points per second) but not total swimming speed (including turns) by entodiniomorphids. Wortmannin decreased both net and total swimming behavior in isotrichids. Results mechanistically explain the isotrichid migratory ecology to rapidly take up newly ingested sugars and subsequent sedimentation back to the ventral reticulorumen. In
\end{abstract}

Received November 8, 2013.

Accepted January 7, 2014.

${ }^{1}$ Current address: Procter and Gamble, 8700 Mason-Montgomery Rd, Mason, $\mathrm{OH} 45040$.

${ }^{2}$ Current address: College of Veterinary Medicine, The Ohio State University, 1900 Coffey Road, Columbus, OH 43210.

${ }^{3}$ Corresponding author: firkins.1@osu.edu contrast, entodiniomorphids apparently integrate cellular motility with feeding behavior to consume small particulates and thereby stay associated and pass with the degradable fraction of rumen particulates. These results extend findings from aerobic ciliate models to explain how rumen protozoa have adapted physiology for their specific ecological niches.

Key words: rumen protozoa, chemotaxis, wortmannin, phagocytosis

\section{INTRODUCTION}

Considerable research has addressed methods to suppress the abundance of ruminal protozoa to decrease intraruminal nitrogen recycling and thereby increase efficiency of dietary protein usage in ruminants (Firkins et al., 2007). As explained therein, the 2 main routes of protozoa-mediated recycling have been attributed to (1) excessive autolysis of the ciliates in the family Isotrichidae (i.e., isotrichids) resulting from excessive glucose uptake followed by cellular disruption or their sequestration in the rumen and (2) extensive predation of bacteria and recycling of bacterial protein by protozoa in the family Ophryoscolecidae (order Entodiniomorphida; i.e., entodiniomorphids). Both mechanisms are related to cilial action for motility and ingestion of substrate, which we aimed to integrate in the current report.

Isotrichids sequester in the ventral reticulorumen, evading passage and decreasing supply of protein to the host, but they rise to the dorsal rumen in waves synchronized with feeding interval (Abe et al., 1981). Although chemotaxis to sugars is intense for isotrichids (Diaz et al., 2014a), postprandial increases in isotrichid abundance in the dorsal rumen occurred even when sheep had an interruption from their habitual feeding schedule and therefore lacked provision of the chemotactic gradient (Dehority and Tirabasso, 1989). Those authors proposed that synthesis of storage carbohydrate probably suppressed migratory behavior until the depletion of storage polysaccharide was sufficient to reinitiate migratory swimming dorsally. Diaz et al. (2014a) documented extensive, dose-responsive chemoattraction by isotrichids to a glucose gradient. 
Diaz et al. (2014b) documented isotrichid chemorepellence from peptides and blocked chemoattraction when glucose was combined with guanosine triphosphate (GTP), which has a proposed receptor and signal transduction mechanism in Tetrahymena (Bartholomew et al., 2008). Isotrichids exhibit diversionary behavior after bumping into particles, as observed under a microscope, probably signifying mechanoreceptors that involve voltage-gated $\mathrm{Ca}^{2+}$ channels (Gonda et al., 2007). Thus, we theorized (Figure 1A) that ruminal protozoa (particularly the isotrichids) regulate motility by varying local $\mathrm{Ca}^{2+}$ concentrations, as described for freshwater ciliates in the genera Paramecium (Valeyev et al., 2009) and Tetrahymena (Lampert et al., 2011).

In contrast to the fully ciliated isotrichids, the numerically predominant entodiniomorphids have cilia only near their anterior region (Dehority, 2003), providing motility but also aiding ingestion of particulate matter (Williams and Coleman, 1992). Chemoattraction by entodiniomorphids to both glucose and peptides, presumably as chemosensory molecules for polysaccharides and proteins from plants and bacteria, was documented to be dose-responsive (Diaz et al., 2014a,b). Our central hypothesis was that moderate but continual chemotaxis would explain why entodiniomorphid protozoa swim in the ruminal fluid while synchronizing their generation time to be similar to the retention time of particles (Karnati et al., 2007; Sylvester et al., 2009), thus lessening intraruminal recycling of microbial protein with increasing feed intakes and ruminal passage rates (Firkins et al., 2007). However, mechanistic evidence to support this premise is lacking. Based on dose-responsive insulin recovery from wortmannin inhibition of growth by 2 entodiniomorphid cultures (Diaz et al., 2014b) and results from Tetrahymena thermophila (Nusblat et al., 2012), we hypothesized coordination of cilial function with ingestion, phagocytosis, and growth rate (particularly for entodiniomorphids) through phosphatidyl inositol 3-kinase (PI3K) signaling (Figure 1B).

Williams and Coleman (1992) summarized studies evaluating selective protozoal predation of bacteria and documenting the magnitude of resultant bacterial turnover. However, these bacteria were typically pulsedosed to starved protozoa, whereas fewer experiments documented that bacterial ingestion was uniformly decreased if the protozoa were simultaneously fed starch or fiber. Thus, predation is probably lower in vivo than in vitro but still extensive (Hristov and Jouany, 2005). The latter authors also summarized studies that documented that protozoal digestion of bacteria takes several hours, limiting our objectives to quantify feeding-associated differences in bacterial uptake over short-term intervals. Stained (dead) bacteria had critical technical and quantitative limitations for study of bacterial predation by Tetrahymena pyriformis (Parry et al., 2001). Earlier studies with rumen protozoal uptake of glass beads had uncertain interpretation of results (Williams and Coleman, 1992). However, recent technology has improved the coating of latex beads to more closely resemble bacterial size and surface charge to assess phagocytosis more accurately (Desjardins and Griffiths, 2003). Epidinium caudatum is less predatory to bacteria compared with Entodinium caudatum (Belanche et al., 2012). The objectives of experiments 1 and 2 were to assess kinetics of fluorescent bead uptake by En. caudatum and Ep. caudatum as affected by the concentration of beads, addition of the chemoattractant glucose, and feeding. We hypothesized that feeding and glucose would decrease rate of bead uptake more for En. caudatum than Ep. caudatum.

Diaz et al. (2014b) reported that sodium nitroprusside [Snp, which generates nitric oxide (NO) to activate protein kinase $\mathrm{G}$ ] increased chemotaxis toward glucose by entodiniomorphids (Figure 1A). Because NO generation is conserved in phospholipase C (PLC)calmodulin signaling in the nonrumen ciliate Tetrahymena, as in other eukaryotes (Bartholomew et al., 2008), we hypothesized in experiment 3 that U73122 (an inhibitor of PLC) would reverse Snp stimulation of chemotactic behavior and limit the amount of fluorescent beads consumed.

Wortmannin enhanced chemotaxis by entodiniomorphids and inhibited growth unless insulin was provided to protozoal cultures (Diaz et al., 2014b). Another hypothesis in experiment 3 was that insulin would further enhance wortmannin's chemotactic response unless blocked by genistein, based on a report using T. thermophila (Leick et al., 1997). Inhibition of PI3K (Leondaritis et al., 2011) and PLC (Moya and Jacobs, 2006) disrupted digestive vacuole function in Tetrahymena, as could be expected from their converged signaling pathways and potential for imbalanced concentration of inositide species (Figure 1B). Therefore, we hypothesized that wortmannin would reverse U73122 inhibition of chemotaxis and limit the amount of beads ingested by mixed ruminal protozoa. To our knowledge, these eukaryotic signaling pathways have not been studied with ruminal ciliates. However, phosphoinositides comprise 3 to $4 \%$ of protozoal lipids (Harfoot and Hazlewood, 1997), indirectly supporting conservation of inositide signaling; moreover, microscopic observations have linked phagocytosis with digestive vacuole formation (Williams et al., 1986).

Because no rumen protozoan genome has yet been sequenced to our knowledge, limiting expression-based approaches, we used motility assays to verify chemotaxis results (Hennessey and Lampert, 2012). In experiment 4, based on our prior study (Diaz et al., 2014b), we 


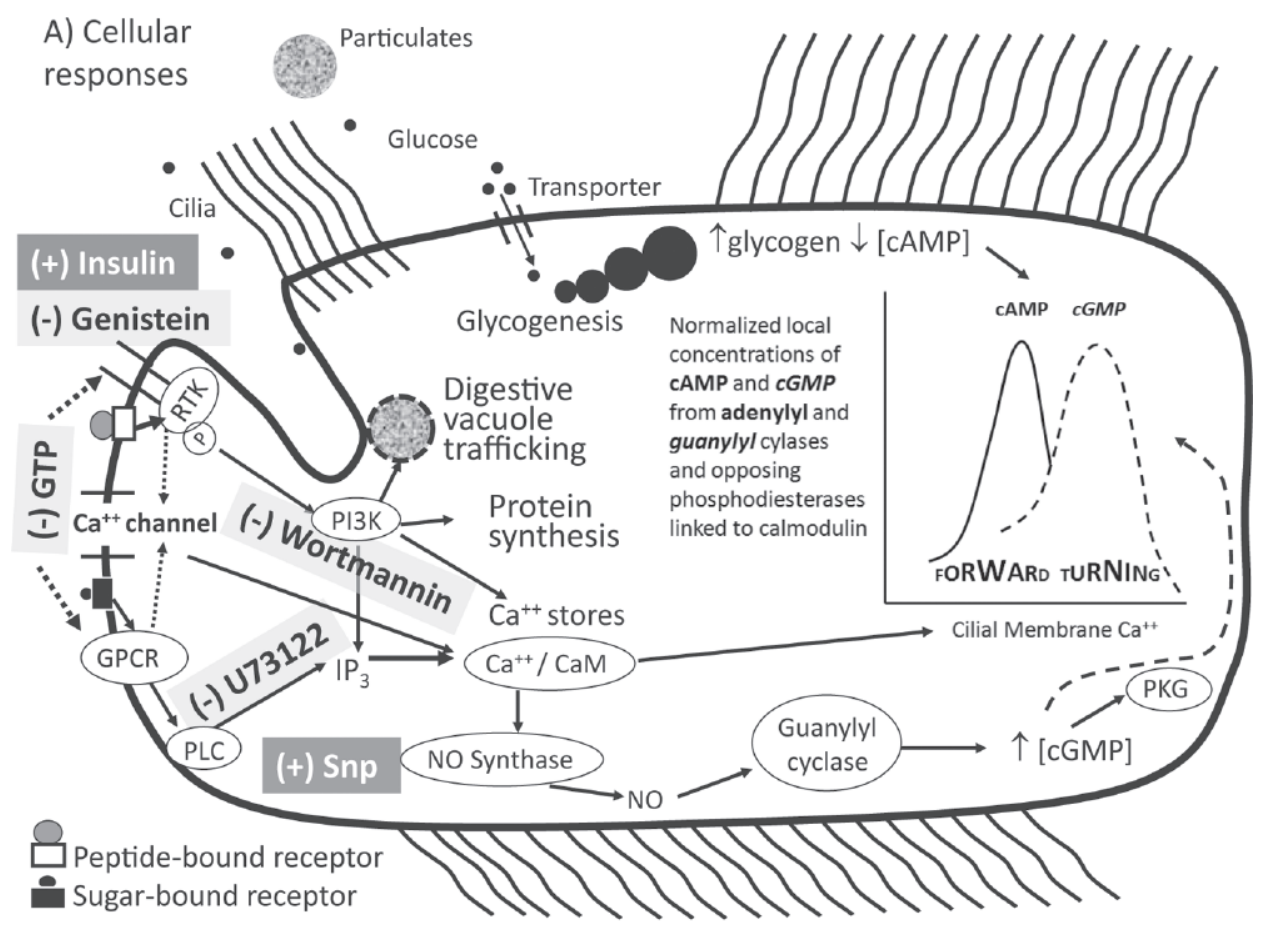

B) Phosphoinositide

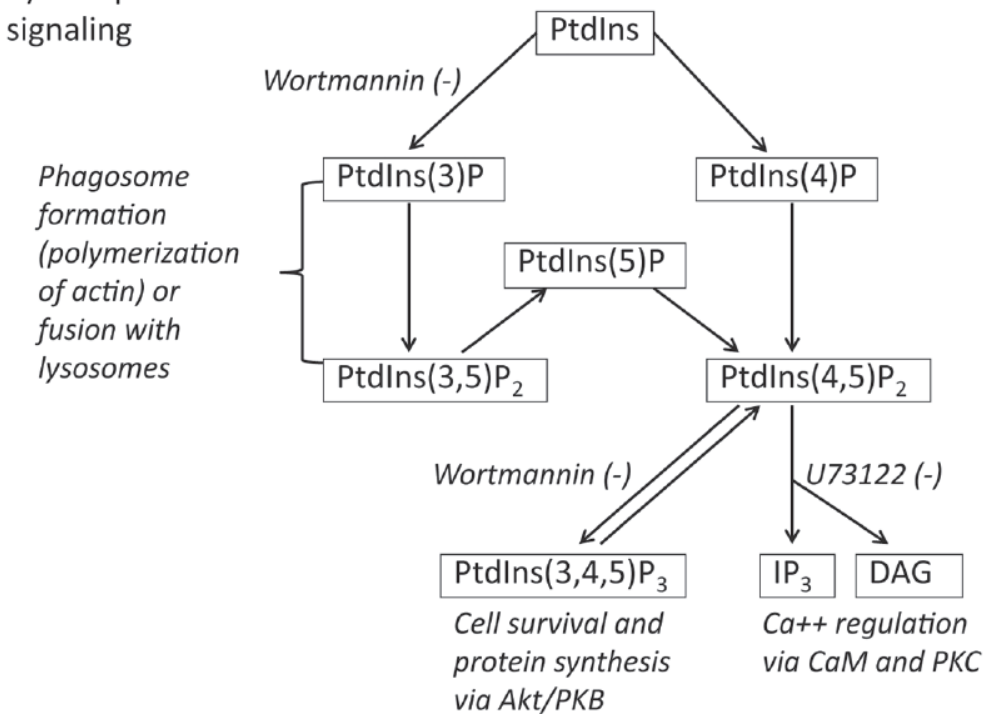

Figure 1. Models used to propose hypotheses for cellular responses (panel A; Bartholomew et al., 2008; Robinette et al., 2008; Lampert et al., 2011) and inositide signaling pathways (panel B; Leondaritis et al., 2011) to explain physiology by ruminal ciliates based on responses from Paramecium and Tetrahymena. In panel A, sugars and amino acids bind to external receptors (left), which should transduce (dashed ar-

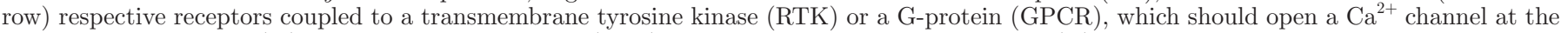
plasma membrane and (or) activate phospholipase C (PLC). Genistein was proposed to inhibit (-) RTK, but insulin was proposed to reverse this block. Guanosine triphosphate (GTP) was proposed to initiate chemorepellence behavior by either RTK or GPCR. Glucose is transported into the cell (top) for glycogenesis, simultaneously increasing energy availability and decreasing cyclic AMP concentration, which should decrease migratory forward swimming (i.e., more net distance traveled per time through a faster net swimming speed). Sodium nitroprusside (Snp) should generate nitric oxide $(\mathrm{NO})$ and activate $(+$ or $\rightarrow$ ) protein kinase $\mathrm{G}(\mathrm{PKG})$ to stimulate directionality toward a chemosensory nutrient gradient (i.e., circling behavior or slower net swimming speed). Increasing $\mathrm{Ca}^{2+}$ concentration in the cilial membrane should increasingly activate calmodulin (CaM)-bound adenylyl and guanylyl cyclases or their opposing phosphodiesterases (insert in right-hand side; Valeyev et al., 2009). In contrast, cilial beating should enhance the ability of entodiniomorphids to ingest particulate matter. Panel B (redrawn and simplified from Nusblat et al., 2012) illustrates pathways of phosphatidylinositide (PtdIns) synthesis and degradation by specific kinases and phosphatases in Tetrahymena. Phosphatidylinositide $(4,5)$ biphosphate $\left(\mathrm{P}_{2}\right)$ is substrate for phosphatidylinositide 3-kinase (PI3K, inhibited by wortmannin) to yield Ptdins $(3,4,5) \mathrm{P}_{3}$ (activates protein kinase B, PKB) or for PLC (inhibited by U73122) to yield inositol $(1,4,5)$ triphosphate $\left(\mathrm{IP}_{3}\right)$ and diacylglycerol (DAG), which can activate protein kinase C (PKC). 
hypothesized that Snp and wortmannin would decrease net distance as a percentage of total distance traveled (i.e., circling behavior) compared with a control, and U73122 was expected to decrease total swimming speed as it did for T. pyriformis (Nam et al., 2009). We assumed that treatments would influence the swimming behavior of the fully ciliated isotrichids to a greater extent than that of entodiniomorphids.

\section{MATERIALS AND METHODS}

\section{Optimizing Fluorescent Bead Density in Protozoal Cultures (Experiment 1)}

In one report, ruminal entodiniomorphid protozoa ingested feed particles ranging from 3 to $19 \mu \mathrm{m}$ (Fondevila and Dehority, 2001), whereas $1 \mu \mathrm{m}$ was reported to be the optimal size in another report (Hristov and Jouany, 2005). Based on preliminary results using 2 sizes $(0.5$ and $6 \mu \mathrm{m})$ of carboxylate-modified latex beads, the $0.5-\mu \mathrm{m}$ diameter optimized bead uptake and improved resolution of single beads when internalized inside protozoa as assessed by fluorescence microscopy. Similar $0.5-\mu \mathrm{m}$ beads have been used with T. pyriformis (Dias et al., 2003), and $0.5 \mu \mathrm{m}$ is in the range of lysosomal structures fractionated from various species of ruminal protozoa (Williams et al., 1986).

Serial dilutions of carboxylate-modified, fluorescent blue latex beads $(0.5 \mu \mathrm{m}$; excitation $\max =360 \mathrm{~nm}$, emission $\max =407 \mathrm{~nm}$; Fluoresbrite; Polysciences Inc., Warrington, PA) with a concentration of $3.64 \times$ $10^{11}$ beads $/ \mathrm{mL}$ were diluted in $0.9 \%$ saline to yield final dilutions of $10^{8}$ and $10^{7}$ beads $/ \mathrm{mL}$. Increasing bead density beyond this dilution layered too many beads at the bottom of culture tubes for sensitive assessment of bead uptake kinetics.

Cultures of En. caudatum were revived from freezing and maintained on 24-h feeding intervals with transfer intervals of $3 \mathrm{~d}$, and the culture volume was increased from 10 to $300 \mathrm{~mL}$, as described by Diaz et al. (2014a). Different replicate tubes were unfed or fed at the proper interval simultaneously with appropriate dosage of beads and incubated for $1 \mathrm{~min}, 20 \mathrm{~min}, 1.0 \mathrm{~h}, 3.0$ $\mathrm{h}$, and $24 \mathrm{~h}$. At respective times, $2 \mathrm{~mL}$ of sample was transferred into 2-mL microcentrifuge tubes containing $40 \mu \mathrm{L}$ of $50 \%$ formalin (bringing the final concentration to $1 \%$ ) and were centrifuged for $2 \mathrm{~min}$ at $500 \times g$. The supernatant was discarded to eliminate free beads, and the pellet was resuspended in $200 \mu \mathrm{L}$ of $0.9 \%$ saline, of which $40 \mu \mathrm{L}$ was placed on a slide. From 100 randomly chosen cells that represented different grids spread over the coverslip, we calculated the percentage of cells that were taking up beads. Data were fit with the PROC NLIN procedure of SAS (version 8.2; SAS Institute
Inc., Cary, NC) using the following model: \% of cells ingesting beads $=A\left(1-\mathrm{e}^{-k t}\right)$, where $A$ is the asymptote, $k$ is the fractional rate constant, and $t$ is time in minutes. Fitted $A$ and $k$ values were analyzed using the MIXED procedure in a randomized complete block design (random blocks for 2 replicate incubations) for a $2 \times 2$ factorial arrangement of treatments (unfed or fed and $10^{7}$ or $10^{8}$ beads $/ \mathrm{mL}$ ). To protect against Type II error, the threshold for significance was uniformly applied at $P \leq 0.10$. However, when $0.05 \leq P \leq 0.10$, we declared the actual $P$-value but maintained a consistent $P>0.10$ cutoff.

\section{Interaction of Feeding with Fluorescent Bead Uptake in Protozoal Cultures (Experiment 2)}

Cultures of En. caudatum and Ep. caudatum were maintained and culture volumes increased before experimentation, as described by Diaz et al. (2014b). Cultures were unfed or fed and either dosed with $0.9 \%$ $\mathrm{NaCl}$ saline vehicle (Sal) or Sal plus glucose (Glc, 58 $\mathrm{m} M$ final glucose, which was the molar equivalent to fed starch) to potentially prevent a chemotactic glucose gradient toward the digesting starch (i.e., because glucose was mixed throughout the entire tube), and were simultaneously dosed to obtain a final dilution of $10^{8}$ beads $/ \mathrm{mL}$ in each tube (based on results from experiment 1). Samples were taken at the same times, processed, counted, and analyzed as described in experiment 1 . The $A$ and $k$ fitted values were assessed in a randomized complete block design (random blocks of 2 incubations) with a $2 \times 2$ factorial arrangement of treatments (unfed or fed, without or with Glc) using the Mixed procedure of SAS.

\section{Preincubation of Inhibitors in Beakers Before Addition of Beads or Capillary Tubes Containing Chemosensory Compounds (Experiment 3)}

Rumen fluid was collected as described (Diaz et al., 2014a) and approved by The Ohio State University's Animal Care and Use Committee. Insulin, genistein, wortmannin, and Snp were used as described previously (Diaz et al., 2014b). The concentration of U73122 (>98\% purity, Sigma-Aldrich, St. Louis, MO) was optimized in a dose-responsive manner before use in the current study. After flocculation, $10 \mathrm{~mL}$ of rumen fluid was pipetted into beakers, and the beakers were placed in an anaerobic chamber to be incubated for $3 \mathrm{~h}$ with (1) $0.9 \% \mathrm{NaCl}$ saline (control), (2) $25 \mu \mathrm{M}$ insulin, (3) $25 \mu M$ insulin $+400 \mu M$ genistein, (4) $500 \mu M$ Snp, (5) $500 \mu M$ Snp $+100 \mu M$ U73122, (6) $200 \mu M$ wortmannin, (7) $200 \mu M$ wortmannin $+25 \mu M$ insulin, (8) $200 \mu M$ wortmannin $+25 \mu M$ insulin $+400 \mu M$ 
genistein, (9) $100 \mu M \mathrm{U} 73122$, (10) $100 \mu M \mathrm{U} 73122+$ $200 \mu M$ wortmannin, or (11) $100 \mu M \mathrm{U} 73122+200 \mu M$ wortmannin $+25 \mu M$ insulin. The vehicle (dimethyl sulfoxide, DMSO, mixed with $0.9 \%$ saline) was the same concentration ( $0.1 \%$ final dilution) in all treatments. The incubation time of $3 \mathrm{~h}$ was based on length of time needed for adaption to PUFA (Diaz et al., 2014a). Wortmannin and U73122 in DMSO have been incubated for as long as $24 \mathrm{~h}$ for T. pyriformis cultures (Nam et al., 2009). These treatments were simultaneously dosed with fluorescent beads $\left(10^{8}\right.$ beads $\left./ \mathrm{mL}\right)$ in each beaker, as justified from results of experiment 1 .

After preincubation of treatments in beakers for $3 \mathrm{~h}$, chemotaxis was assessed using capillary tubes that were not filled and remained unsealed (UN) or were filled with $0.9 \%$ Sal, $1 M$ Glc, $1 \mathrm{~g} / \mathrm{L}$ of soluble peptides, 1 $M$ Glc $+1 \mathrm{~g} / \mathrm{L}$ of soluble peptides, or $1 \mathrm{~g} / \mathrm{L}$ of soluble peptides $+100 \mu M$ GTP. Diaz et al. (2014a) verified the assay and justified the concentrations of glucose and peptides, and a subsequent report (Diaz et al., 2014b) documented the concentration of GTP.

Triplicates of 20-min counts (adjusted for 0-min counts) were averaged per replicate. Counts from the sealed tubes were normalized to $\log _{10}$ and covariate-adjusted for UN (Diaz et al., 2014a). Data were analyzed using the Mixed procedure of SAS for a randomized complete block design (random blocks for 3 replicate incubations) for an $11 \times 5$ factorial arrangement (11 beaker treatments $\times 5$ capillary tube treatments). Because interactions were detected $(P<0.05)$ for both entodiniomorphids (Table 1) and isotrichids (Table 2 ), beaker treatment means within each capillary tube treatment were compared by least significant difference (protected by the Slice option). Comparisons were restricted to individual means compared with the control or to the treatment with one successive addition of compound to decrease Type I error. Three preplanned contrasts assessed the main effects and interactions of glucose and peptides in the $2 \times 2$ factorial arrangement of sealed capillary tube treatments (excluding GTP). A fourth comparison was peptides versus peptides + GTP. The threshold for significance was uniformly applied at $P \leq 0.10$. However, when $0.05 \leq P \leq 0.10$, we declared the actual $P$-value but maintained a consistent $P>0.10$ cutoff.

To assess bead uptake, we counted the number of beads within each of 100 random cells of entodiniomorphids recovered from inside capillary tubes, as described previously. The isotrichids were too few for any meaningful quantitative and statistical assessment of treatments but were observed to incorporate beads (data not shown). Results were divided into bins $(0,1$ to

Table 1. Covariate-adjusted $\log _{10}$ counts of entodiniomorphids in unfilled and unsealed (UN) capillary tubes or in capillary tubes that were filled with chemosensing compounds before being sealed and inserted into beakers that were preincubated for $3 \mathrm{~h}$ in rumen fluid containing combinations of sensitizing compounds in experiment 3

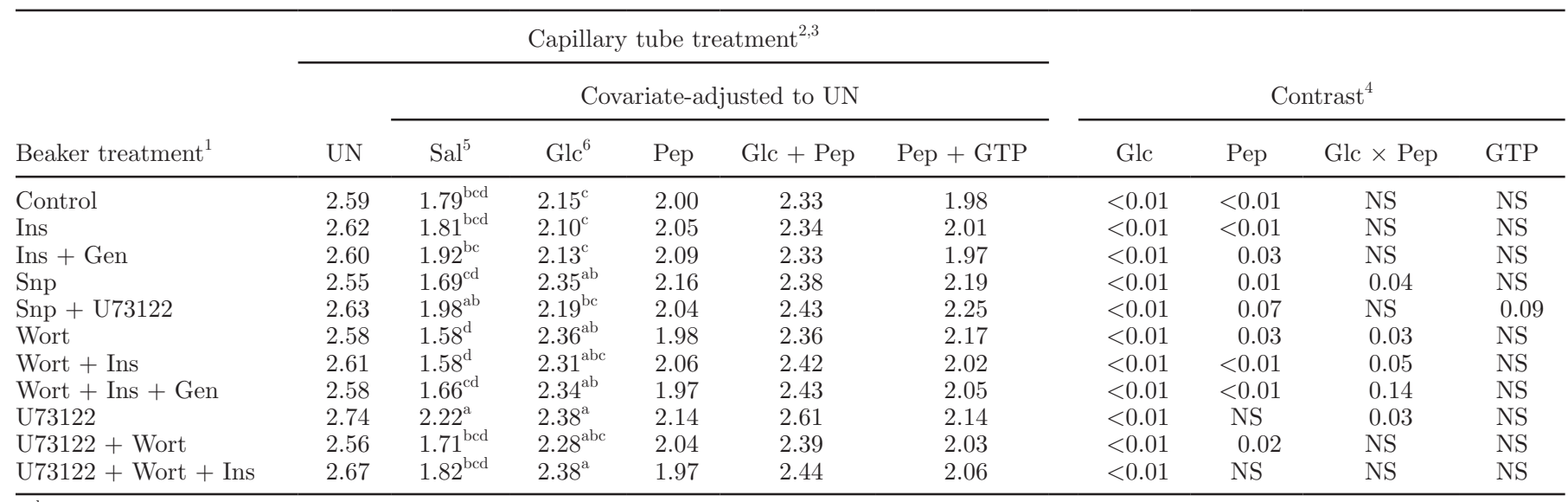

\footnotetext{
${ }^{\mathrm{a}-\mathrm{d}}$ Means within a column with different superscripts differ $(P \leq 0.05)$.

${ }^{1}$ Ruminal fluid in beakers with a control (0.1\% dimethyl sulfoxide, DMSO) or DMSO with insulin (Ins), genistein (Gen), sodium nitroprusside (Snp), U73122, or wortmannin (Wort) alone or in combination.

${ }^{2}$ Unsealed (UN) capillary tubes were used to standardize protozoal counts among beakers. No beaker treatment effects $(P>0.15)$ were observed for UN. Pooled SEM were 0.07 for capillary tube treatments and 0.08 for beaker treatments.

${ }^{3}$ Capillary tube treatments were filled with saline (Sal), $1 M$ glucose (Glc), $1 \mathrm{~g} / \mathrm{L}$ of peptides (Pep), Glc + Pep, or Pep $+100 \mu M$ guanosine triphosphate (GTP) before sealing. When covariate-adjusted to UN, we detected a beaker treatment $\times$ capillary tube treatment $(P=0.02)$.

${ }^{4}$ Contrasts among covariate-adjusted means or combined means (within parentheses): Glc $=($ Sal and Pep) versus $($ Glc and Glc + Pep $)$, Pep $=$ $($ Sal and Glc) versus (Pep and Glc + Pep $)$, Glc $\times$ Pep $=($ Sal and Glc + Pep) versus (Glc and Pep), and GTP $=$ Pep versus Pep + GTP. NS $=P>0.15$.

${ }^{5}$ Saline capillary tube treatments had a significant slice $(P=0.02)$ to protect the LSD comparisons within column.

${ }^{6}$ Glucose capillary tube treatments had a significant slice $(P=0.08)$ to protect the LSD comparisons within column.
} 
Table 2. Covariate-adjusted $\log _{10}$ counts of isotrichids in unfilled and unsealed (UN) capillary tubes or in capillary tubes that were filled with chemosensing compounds before being sealed and inserted into beakers that were preincubated for $3 \mathrm{~h}$ in rumen fluid containing combinations of sensitizing compounds in experiment 3

\begin{tabular}{|c|c|c|c|c|c|c|c|c|c|c|}
\hline \multirow[b]{2}{*}{ Beaker treatment $^{1}$} & \multicolumn{6}{|c|}{ Capillary tube treatment ${ }^{2,3}$} & & & & \\
\hline & UN & $\mathrm{Sal}^{5}$ & $\mathrm{Glc}^{6}$ & Pep & $\mathrm{Glc}+\mathrm{Pep}$ & Pep + GTP & Glc & Pep & Glc $\times$ Pep & GTP \\
\hline Control & 0.95 & 0.58 & $1.87^{\mathrm{a}}$ & 0.33 & 0.68 & 0.42 & $<0.01$ & $<0.01$ & 0.05 & NS \\
\hline Ins & 0.96 & 0.59 & $1.76^{\mathrm{ab}}$ & 0.06 & 0.83 & 0.48 & $<0.01$ & $<0.01$ & NS & 0.09 \\
\hline Ins + Gen & 0.99 & 0.44 & $1.32^{\mathrm{bcd}}$ & 0.29 & 0.68 & 0.41 & $<0.01$ & $<0.01$ & 0.09 & NS \\
\hline Wort & 0.92 & 0.65 & $1.29^{\mathrm{cd}}$ & 0.33 & 0.94 & 0.50 & $<0.01$ & 0.06 & NS & NS \\
\hline Wort + Ins & 0.88 & 0.56 & $1.17^{\mathrm{cd}}$ & 0.43 & 0.85 & 0.38 & 0.03 & NS & NS & NS \\
\hline Wort + Ins + Gen & 0.93 & 0.72 & $0.92^{\mathrm{d}}$ & 0.28 & 0.82 & 0.24 & 0.13 & NS & NS & NS \\
\hline U73122 & 1.07 & 0.77 & $1.60^{\mathrm{abc}}$ & 0.43 & 0.81 & 0.34 & $<0.01$ & $<0.01$ & 0.12 & NS \\
\hline $\mathrm{U} 73122+$ Wort & 0.78 & 1.08 & $0.85^{\mathrm{d}}$ & 0.54 & 0.56 & 0.51 & NS & 0.04 & NS & NS \\
\hline $\mathrm{U} 73122+$ Wort + Ins & 0.97 & 0.98 & $1.01^{\mathrm{d}}$ & 0.18 & 0.54 & 0.50 & 0.04 & $<0.01$ & NS & 0.11 \\
\hline
\end{tabular}

\footnotetext{
${ }^{\mathrm{a}-\mathrm{d}}$ Means within a column with different superscripts differ $(P \leq 0.05)$.

${ }^{1}$ Ruminal fluid in beakers with a control (0.1\% dimethyl sulfoxide, DMSO) or DMSO with insulin (Ins), genistein (Gen), sodium nitroprusside (Snp), U73122, or wortmannin (Wort) alone or in combination.

${ }^{2}$ Unsealed (UN) capillary tubes were used to standardize protozoal counts among beakers. No beaker treatment effects $(P>0.15)$ were detected for UN. Pooled SEM were 0.13 for capillary tube treatments and 0.16 for beaker treatments.

${ }^{3}$ Capillary tube treatments were filled with saline (Sal), $1 M$ glucose (Glc), $1 \mathrm{~g} / \mathrm{L}$ of peptides (Pep), Glc + Pep, or Pep $+100 \mu M$ guanosine triphosphate (GTP) before sealing. When covariate-adjusted to UN, a beaker treatment $\times$ capillary tube treatment $(P<0.01)$ was detected.

${ }^{4}$ Contrasts among covariate-adjusted means or combined means (within parentheses): Glc $=($ Sal and Pep) versus $($ Glc and Glc + Pep), Pep $=$ $($ Sal and Glc) versus $($ Pep and Glc + Pep $)$, Glc $\times$ Pep $=($ Sal and Glc + Pep) versus (Glc and Pep), and GTP $=$ Pep versus Pep + GTP. NS $=P>0.15$.

${ }^{5}$ Saline capillary tube treatments had a significant slice $(P=0.02)$ to protect the LSD comparisons within column.

${ }^{6}$ Glucose capillary tube treatments had a significant slice $(P=0.01)$ to protect the LSD comparisons within column.
}

5, 6 to 10, 11 to 15 , or $>16$ beads per entodiniomorphid protozoan) to improve counting efficiency and reduce variability. Because no interaction was detected between beaker and capillary tube treatment $(P>0.15)$, main effect means for bead uptake counts (Tables 3 and 4) were analyzed as for the chemotaxis data with one exception: the UN capillary tubes were retained in the analysis of beads because the cells were already scaled as a proportion; an orthogonal contrast compared the UN treatment to the average of the sealed capillary tube treatments.

\section{Total and Net Swimming Speed of Protozoa (Experiment 4)}

Swimming behavior videography was done in 3 incubations of mixed ruminal fluid taken approximately 3 $\mathrm{h}$ after a cow was fed a standard lactation diet. Mixed ruminal microbes were preincubated with control $(0.9 \%$ saline) or with Sal plus Snp, wortmannin, or U73122 (all dissolved in DMSO) at the same dosages as those described previously. Treatments were preincubated with $10 \mathrm{~mL}$ of ruminal fluid anaerobically at $39^{\circ} \mathrm{C}$ in glass culture tubes with rubber stoppers $(2$ replicates per treatment), each staggered by $20 \mathrm{~min}$ to maintain a constant 180-min incubation (i.e., the same time as in experiment 3). After inversion to mix the incubations, $40-\mu \mathrm{L}$ samples were placed on a glass slide. At each point of a $5 \times 5$ matrix on the coverslip, a 10-s video was recorded, and the stage was quickly moved to the next point until all 25 video recordings were completed. Videography was performed over the 3 blocks such that the cumulative experiment had all 4 treatments averaging the same amount of time after samples were taken from the rumen or dosing the chemosensory compounds.

From each of the videos, 2 entodiniomorphid cells near the center of the focal path were randomly chosen before recording, but all of the less numerous isotrichids were evaluated. Using VLC Media Player (open source software; VideoLAN, Paris, France), the selected protozoa were traced from the computer monitor frame by frame, and the tracing was subsequently measured by hand using a ruler that was graduated into millimeters and scaled using a stage micrometer, as previously described (Leick et al., 1997). The total distance (including turning) and net distance (excluding turning) were measured. We omitted a minority of cells $(<25 \%)$ with no total movement or that had interrupted paths (e.g., bumping into other protozoa). In the final analysis, entodiniomorphids and isotrichids were represented by $\geq 185$ or $\geq 20$ tracings (over all 6 replicates), respec- 
Table 3. Proportion of entodiniomorphids that were inside capillary tubes but had taken up 0.5- $\mu \mathrm{m}$ carboxylated beads loaded into beakers containing ruminal fluid that had been preincubated for $3 \mathrm{~h}$ with combinations of sensitizing compounds in experiment $3^{1}$

\begin{tabular}{lccccc}
\hline & \multicolumn{5}{c}{ Proportion of protozoa binned for the number of beads per cell } \\
\cline { 2 - 5 } Beaker treatment $^{2}$ & Zero beads & 1 to 5 beads & 6 to 10 beads & 11 to 15 beads & $>16$ beads \\
\hline Control & $0.090^{\mathrm{e}}$ & $0.374^{\mathrm{a}}$ & $0.185^{\mathrm{b}}$ & $0.113^{\mathrm{a}}$ & $0.238^{\mathrm{a}}$ \\
Control + Ins & $0.095^{\mathrm{e}}$ & $0.380^{\mathrm{a}}$ & $0.216^{\mathrm{a}}$ & $0.100^{\mathrm{ab}}$ & $0.208^{\mathrm{a}}$ \\
Control + Ins + Gen & $0.116^{\mathrm{de}}$ & $0.374^{\mathrm{a}}$ & $0.195^{\mathrm{b}}$ & $0.090^{\mathrm{ab}}$ & $0.225^{\mathrm{a}}$ \\
Snp & $0.120^{\mathrm{de}}$ & $0.316^{\mathrm{ab}}$ & $0.209^{\mathrm{ab}}$ & $0.105^{\mathrm{ab}}$ & $0.250^{\mathrm{a}}$ \\
Snp + U73122 & $0.176^{\mathrm{d}}$ & $0.386^{\mathrm{a}}$ & $0.205^{\mathrm{ab}}$ & $0.083^{\mathrm{b}}$ & $0.151^{\mathrm{b}}$ \\
Wort & $0.572^{\mathrm{b}}$ & $0.360^{\mathrm{a}}$ & $0.044^{\mathrm{c}}$ & $0.012^{\mathrm{c}}$ & $0.013^{\mathrm{c}}$ \\
Wort + Ins & $0.500^{\mathrm{c}}$ & $0.392^{\mathrm{a}}$ & $0.047^{\mathrm{c}}$ & $0.028^{\mathrm{c}}$ & $0.033^{\mathrm{c}}$ \\
Wort + Ins + Gen & $0.558^{\mathrm{b}}$ & $0.358^{\mathrm{a}}$ & $0.037^{\mathrm{c}}$ & $0.019^{\mathrm{c}}$ & $0.027^{\mathrm{c}}$ \\
U73122 & $0.133^{\mathrm{de}}$ & $0.352^{\mathrm{a}}$ & $0.224^{\mathrm{a}}$ & $0.076^{\mathrm{b}}$ & $0.215^{\mathrm{a}}$ \\
U73122 + Wort & $0.610^{\mathrm{b}}$ & $0.323^{\mathrm{ab}}$ & $0.031^{\mathrm{c}}$ & $0.012^{\mathrm{c}}$ & $0.024^{\mathrm{c}}$ \\
U73122 + Wort + Ins & $0.727^{\mathrm{a}}$ & $0.255^{\mathrm{b}}$ & $0.013^{\mathrm{c}}$ & $0.003^{\mathrm{c}}$ & $0.002^{\mathrm{c}}$ \\
\hline
\end{tabular}

${ }^{a}$ Means within a column with different superscripts differ $(P \leq 0.05)$.

${ }^{1}$ Main effect means were averaged over capillary tube treatments within beaker treatment. No capillary tube $\times$ beaker treatment interaction $(P>0.15)$ was detected. See Table 4 for main effect means for capillary tube treatments. The pooled SEM was 0.029 .

${ }^{2}$ Ruminal fluid in beakers with a control (0.1\% dimethyl sulfoxide, DMSO) or DMSO with insulin (Ins), genistein (Gen), sodium nitroprusside (Snp), U73122, or wortmannin (Wort) alone or in combination.

tively, for each of the 4 treatments. To account for the large random variability among cells, we calculated the respective standard deviation (SD) for each mean of total and net movement per replicate (experimental unit). Using a weight of $1 / \mathrm{SD}^{2}$, the model included the fixed effects of block and treatment and was analyzed using Proc Mixed of SAS (SAS Institute Inc.). Each of the 3 treatments was compared with the control with a $t$-test.

\section{RESULTS}

\section{Interaction of Feeding with Fluorescent Bead Uptake (Experiments 1 and 2)}

Microscopic visualization routinely documented internalization of beads, sometimes displaying structured patterns as shown in Supplementary Figure S1, panel A (http://dx.doi.org/10.3168/jds.2013-7698). Recovered

Table 4. Proportion of entodiniomorphids that had taken up $0.5-\mu \mathrm{m}$ carboxylated beads loaded into beakers containing rumen fluid but recovered from the inside of capillary tubes that were unfilled and unsealed or that were filled with saline, glucose, soluble peptides, glucose + peptides, or guanosine triphosphate (GTP) before sealing and inserting into the beakers in experiment $3^{1}$

\begin{tabular}{lccccc}
\hline & \multicolumn{4}{c}{ Proportion of protozoa binned for the number of beads per cell } \\
\cline { 2 - 5 } Item & Zero beads & 1 to 5 beads & 6 to 10 beads & 11 to 15 beads & $>16$ beads \\
\hline Capillary tube treatment & & & & & \\
Unfilled and unsealed & 0.376 & 0.333 & 0.122 & 0.050 & 0.120 \\
Saline & 0.327 & 0.362 & 0.139 & 0.057 & 0.115 \\
Glucose & 0.343 & 0.301 & 0.120 & 0.063 & 0.174 \\
Peptides & 0.332 & 0.399 & 0.122 & 0.051 & 0.097 \\
Glucose + peptides & 0.372 & 0.336 & 0.119 & 0.052 & 0.122 \\
Peptides + GTP & 0.311 & 0.391 & 0.126 & 0.062 & 0.111 \\
Contrast probabilities & & & & & NS \\
Unsealed versus sealed & 0.03 & NS & NS & NS & $<0.01$ \\
Glucose & 0.08 & $<0.01$ & NS & NS & 0.01 \\
Peptides & NS & 0.06 & NS & NS & NS \\
Glucose $\times$ peptides & NS & NS & NS & NS & NS \\
GTP effect & NS & NS & NS & \\
\hline
\end{tabular}

${ }^{1}$ Main effect means are averaged over 3-h beaker pretreatments within capillary tube treatment. No capillary tube $\times$ beaker treatment interaction $(P>0.15)$ was detected. See Table 3 for main effect means for beaker treatments. The pooled SEM was 0.017.

${ }^{2}$ Contrasts for the unsealed treatment versus average of the 5 sealed treatments, main effect of glucose, main effect of peptides, glucose $\times$ peptide interaction, and peptides versus GTP + peptides, respectively. NS $=P$ $>0.15$. 


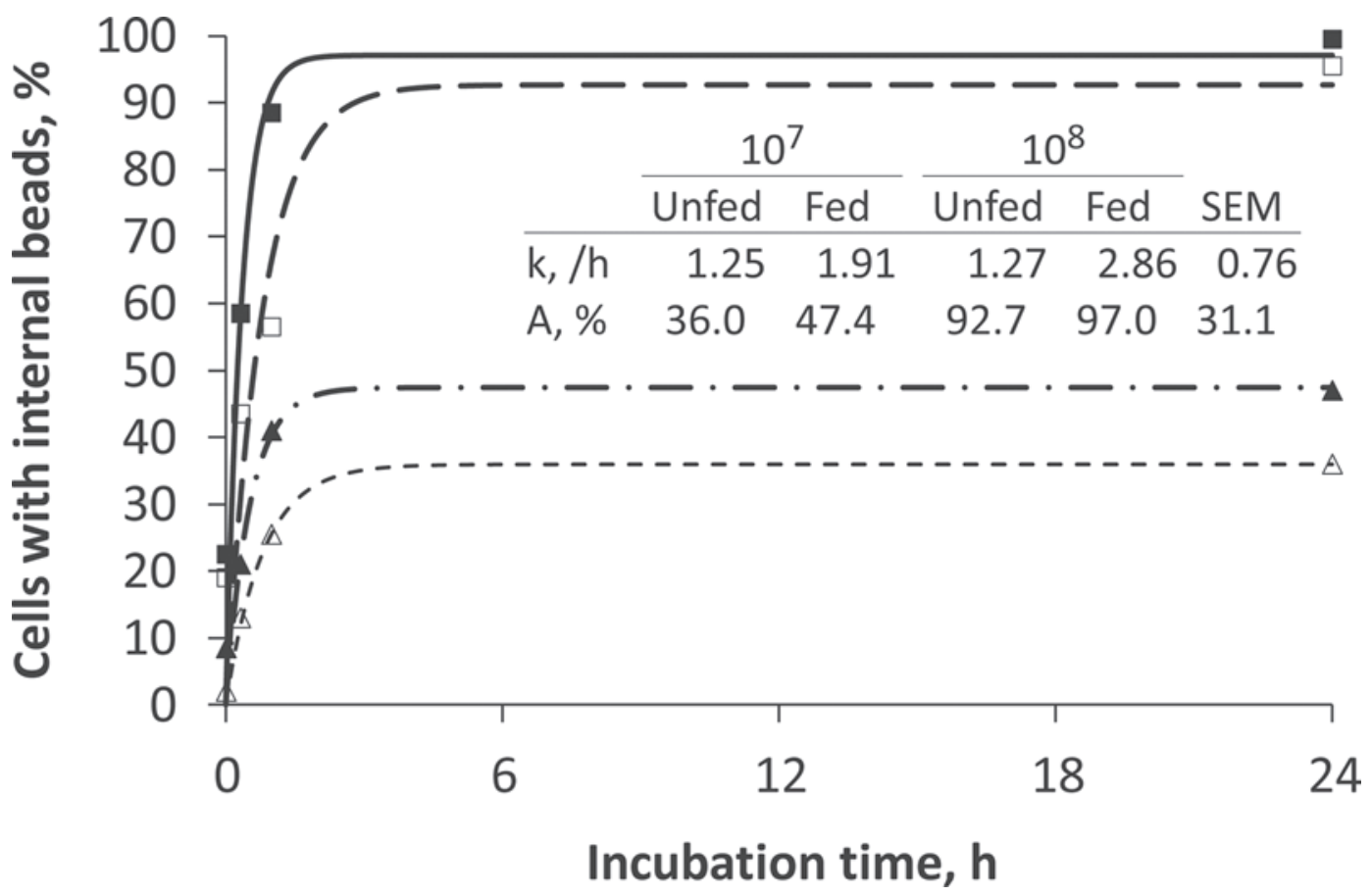

Figure 2. Percentage of Entodinium caudatum cells in culture that had at least one fluorescent bead with increasing time after dosage of $10^{7}$ or $10^{8}$ beads $/ \mathrm{mL}$ without or simultaneously with feeding in experiment 1 . Curves were fit using the monoexponential model, $\%$ of cells with at least one ingested bead $=A\left(1-\mathrm{e}^{-k t}\right)$, where $A=$ asymptotic bead uptake (\% of cells), $t=$ time in minutes, and $k=$ fractional rate of uptake

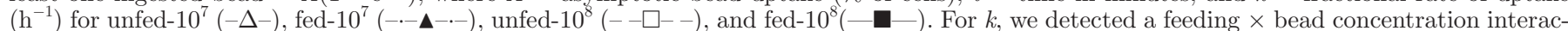
tion $(P=0.08)$, a main effect of feeding $(P<0.01)$, and a main effect of bead concentration $(P=0.07)$. For the asymptotic $A$ term, we detected no feeding $\times$ bead concentration interaction or main effect of feeding $(P>0.10)$ but did detect a main effect of bead concentration $(P<0.01)$.

cells also documented the vesicularization of some of those internalized beads (Supplementary Figure S1, panel B; http://dx.doi.org/10.3168/jds.2013-7698). Rate of bead uptake by En. caudatum had a feeding $\times$ bead concentration interaction $(P=0.08)$, which was explained by the fed treatment increasing the rate for $10^{8}$ beads $/ \mathrm{mL}$ more than it did for $10^{7}$ beads $/ \mathrm{mL}$ (Figure 2). Asymptotic bead uptake had no feeding $\times$ bead concentration interaction or main effect of feeding $(P>$ $0.10)$. However, the main effect mean for $10^{7}$ beads was lower $(P<0.01)$ by more than half compared with that for $10^{8}$ beads $/ \mathrm{mL}$.

For En. caudatum (Figure 3A), the main effect of rate of bead uptake was explained by the main effect mean for the fed treatment being lower $(P<0.01)$ than that for unfed treatment. The interaction for asymptotic bead uptake $(P=0.01)$ was explained by feeding increasing the percentage of protozoa taking up beads asymptotically when no glucose was added, but unfed versus fed had no effect when glucose was added. For Ep. caudatum (Figure 3B), the main effect means for the rate of bead uptake were lower $(P<0.01)$ for the unfed treatment when compared with the fed treatment. The main effect mean for glucose was greater $(P$ $=0.09)$ than that without glucose. Asymptotic bead uptake was not affected $(P>0.10)$ by treatment.

\section{Preincubating Beaker Inhibitors and Activators to Regulate Chemosensory Responses to Glucose or Peptides (Experiment 3)}

For entodiniomorphids (Table 1 ), the $\log _{10}$ counts in UN capillary tubes did not differ $(P>0.10)$ among preincubation treatments $($ mean $=2.61)$. We detected an interaction $(P=0.02)$ between preincubation beaker treatments and sealed capillary chemoattractant treatments. The Slice command of SAS only supported comparisons among means within capillary tube treatment for saline $(P=0.02)$ and glucose $(P=0.08)$.

When comparing beaker treatments exclusively within the column for the sealed capillary tubes containing Sal (no chemosensory agents; Table 1), insulin, genistein, Snp, or wortmannin had no effect $(P$ $>0.10)$ compared with the beaker control treatment for entodiniomorphids (Table 1). However, U73122 increased $(P<0.05)$ counts in the Sal capillary tubes compared with the beaker control treatment (2.22 vs $1.79 \log _{10}$ counts), and random swimming into Sal capillary tubes was greater $(P<0.05)$ when U73122 was combined with Snp than for Snp alone (1.98 vs 1.69 $\log _{10}$ counts). However, the addition of wortmannin to U73122 blocked $(P<0.05)$ the U73122 response $(1.71$ vs $2.22 \log _{10}$ counts). 


\section{A) Entodinium caudatum}

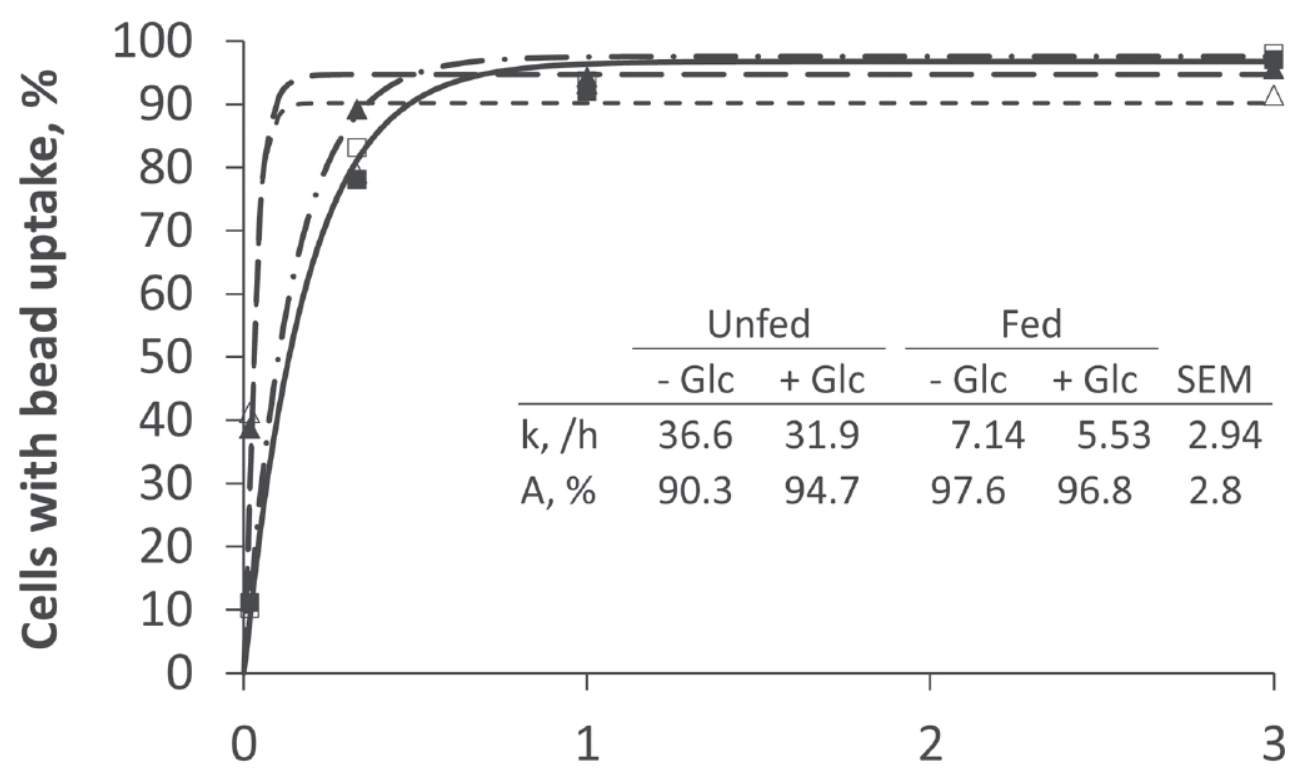

B) Epidinium caudatum

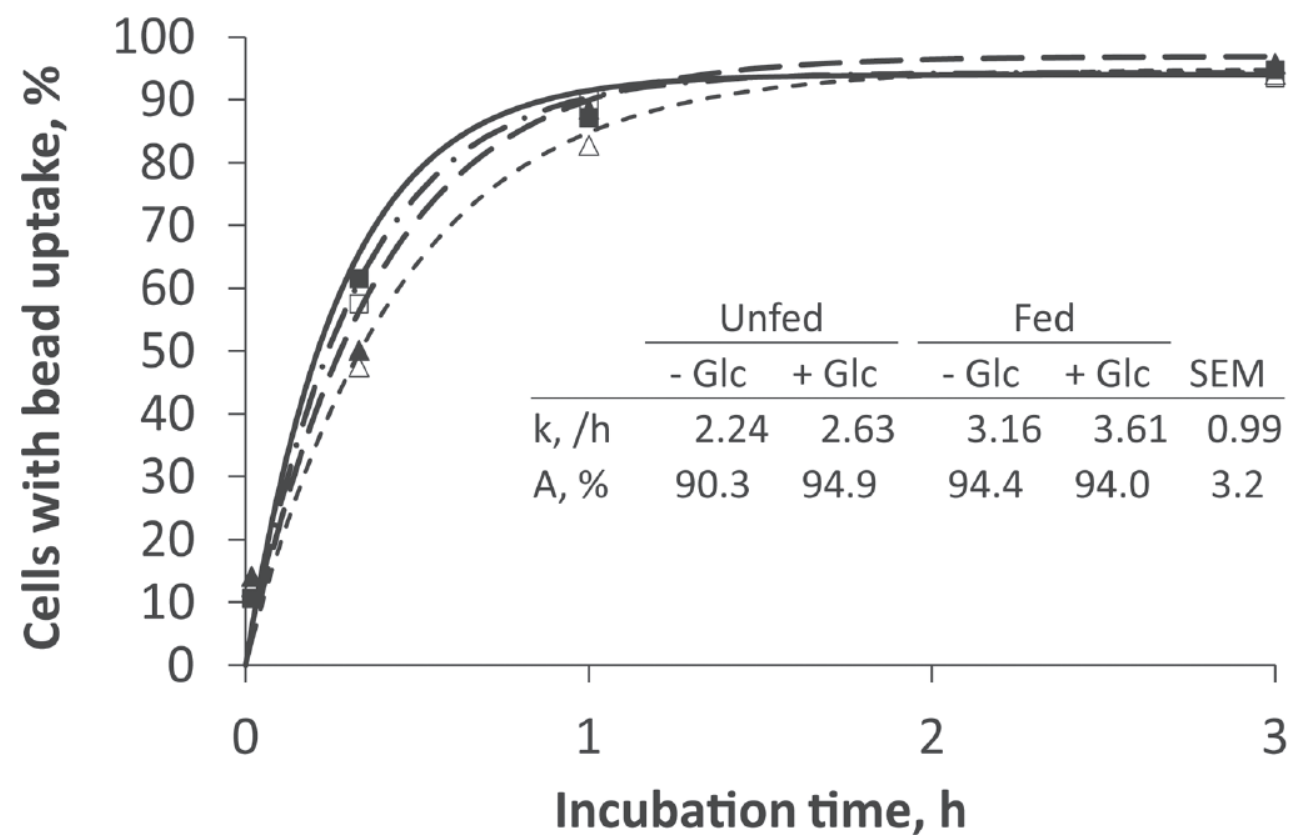

Figure 3. Percentage of 2 protozoal cultures that had at least one fluorescent bead with increasing time after bead dosage without (unfed) or simultaneously with (fed) feeding and without (NoGlc) or with (Glc) glucose in experiment 2. Curves were fit using the monoexponential model, $\%$ of cells with at least one ingested bead $=A\left(1-\mathrm{e}^{-k t}\right)$, where $A=$ asymptotic bead uptake ( $\%$ of cells), $t=$ time in minutes, and $k=$ fractional rate of uptake $\left(\mathrm{h}^{-1}\right)$ for unfed-NoGlc $\left(-\Delta_{-}^{-}\right)$, fed-NoGlc $\left(-\cdot-\boldsymbol{\Delta}_{---}\right)$, unfed-Glc $(--\square--)$, and fed-Glc $(-\mathbf{-}-)$. Panel A represents data for Entodinium caudatum. For $k$, we detected no feeding $\times$ glucose interaction $(P>0.10)$, a main effect of feeding $(P<0.01)$, but no main effect of glucose dosage $(P>0.10)$. For the asymptotic $A$ term, we detected a feeding $\times$ glucose dosage interaction $(P=0.01)$, a main effect of feeding $(P<0.01)$, and a main effect of glucose dosage $(P=0.06)$. Panel B represents data for Epidinium caudatum. For $k$, we detected no feeding $\times$ glucose interaction $(P>0.10)$, a main effect of feeding $(P<0.01)$, and a main effect of glucose dosage $(P=0.09)$. For the asymptotic $A$ term, we detected no feeding $\times$ glucose dosage interaction $(P>0.10)$, no main effect of feeding $(P>0.10)$, and no main effect of bead concentration $(P>0.10)$. 
When comparing entodiniomorphid counts exclusively within the column for the sealed capillary tubes containing Glc (Table 1), neither insulin nor genistein preincubated into beakers had any effect $(P>0.10)$ compared with the control beaker treatment. However, addition of Snp, wortmannin, or U73122 to beakers increased $(P \leq 0.05)$ chemotaxis toward Glc in sealed capillary tubes $\left(2.35,2.36\right.$, and $2.38 \log _{10}$ counts, respectively) compared with the control (2.15 $\log _{10}$ counts). The combination of Snp and U73122 did not affect $(P>0.10)$ chemotaxis toward Glc. Other combinations of beaker treatments were without effect $(P$ $>0.10)$.

The $\log _{10}$ counts of isotrichids in unsealed capillary tubes did not differ $(P=0.19$; mean $=0.94)$ among beaker treatment (Table 2). We detected an interaction $(P<0.01)$ among preincubation beaker treatments and sealed capillary tube treatments. Beaker treatments were only different for Glc $(P<0.01)$, as assessed by the Slice command.

Exclusively within the column for the sealed capillary tubes containing Glc, insulin did not affect $(P>0.10)$ chemotaxis compared with the beaker control treatment for isotrichids (Table 2). Insulin plus genistein in the beakers decreased $(P<0.05)$ chemotaxis toward Glc when compared with the beaker control but not when compared with insulin alone $(P>0.10)$. Neither Snp nor U73122 beaker treatments affected chemotaxis toward Glc $(P>0.10)$. However, when compared with the control, wortmannin decreased $(P<0.05)$ chemotaxis toward Glc, and neither insulin nor genistein addition to beakers altered this response. When combined with U73122, wortmannin decreased $(P<0.05)$ chemotaxis toward Glc compared with U73122 alone, and the decrease of chemotaxis caused by wortmannin was not reversed $(P>0.10)$ by also adding insulin. Thus, wortmannin consistently decreased chemotaxis of isotrichids to Glc.

When evaluating across capillary tube treatments (rows in Table 2), contrasts documented consistently high chemoattraction by isotrichids toward Glc $(P<$ 0.01 for main effect of glucose), although contrasts lost significance when wortmannin was combined with insulin + genistein or with U73122. The main effect of peptides was generally consistent $(P \leq 0.06)$ except for 2 of the beaker treatments containing wortmannin (combined with insulin or with genistein). Repellence by peptides often was enough to overcome chemoattraction by Glc (i.e., Glc $\times$ peptide interaction, $P \leq$ 0.09). The interaction lost significance in all 5 treatments in which addition of wortmannin to beakers blunted chemotaxis.

For entodiniomorphids, we detected no interaction $(P$ $>0.10)$ between beaker and capillary tube treatments for bead uptake for any of the bins (Table 3). For the main effect means of beaker treatments (averaged over capillary tube treatments), no effect $(P>0.10)$ of insulin, genistein, or Snp was detected for the proportion of protozoa without beads (i.e., in the zero beads column). However, addition of wortmannin to beakers increased $(P \leq 0.05)$ the proportion of protozoa without beads compared with the control beaker treatment. Insulin partly counteracted $(P<0.05)$ wortmannin's inhibition, but the proportion of cells without beads was still higher $(P<0.05)$ than the control. In contrast, the addition of genistein to wortmannin + insulin increased $(P<0.05)$ the proportion of cells without beads. We detected no effect $(P>0.10)$ of U73122 addition to beakers on the proportion of cells without beads when compared with the control beaker treatment. However, the proportion of cells without beads in the U73122 beaker treatment increased $(P<0.05)$ when wortmannin was added, and this effect was exacerbated $(P<$ $0.05)$ when insulin was added to U73122 + wortmannin. Overall, the overwhelming response was for wortmannin to increase the proportion of cells without beads, particularly resulting from the lower proportion of cells with $>16$ beads.

For the main effect means of capillary tube treatments averaged over beaker treatments (Table 4), entodiniomorphids had a higher proportion of cells that had no internalized beads for the UN treatment (0.376) compared with the average of the sealed capillary tube treatments (0.337; data not shown). The main effect of glucose $(P=0.08)$ resulted from the main effect mean of Glc and Glc + peptides (0.358) being greater than the main effect mean of Sal and peptides (0.330; data not shown). The main effect means for glucose were lower $(P<0.01)$ for the bin with 1 to 5 beads because the main effect means were higher $(P<0.01)$ for the bin with $>16$ beads/cell compared with the respective main effect means without Glc. In contrast to Glc effects, peptides increased $(P=0.06)$ the proportion of cells with 1 to 5 beads but decreased $(P=0.01)$ the proportion of cells with $>16$ beads per cell.

\section{Total and Net Swimming Speed by Protozoa Incubated with Selected Compounds (Experiment 4)}

For entodiniomorphids, net speed was lower for wortmannin $(P=0.06)$ and $\operatorname{Snp}(P=0.08)$ than the control (Figure 4A). When net swimming speed was calculated as a percentage of total swimming speed, both wortmannin and Snp were lower $(P<0.05)$ than the control. For isotrichids (Figure 4B), wortmannin decreased $(P<0.05)$ both total and net swimming speeds; thus, when net was expressed as a percentage of total, treatments were similar $(P>0.10)$. 


\section{A) Entodiniomorphids}

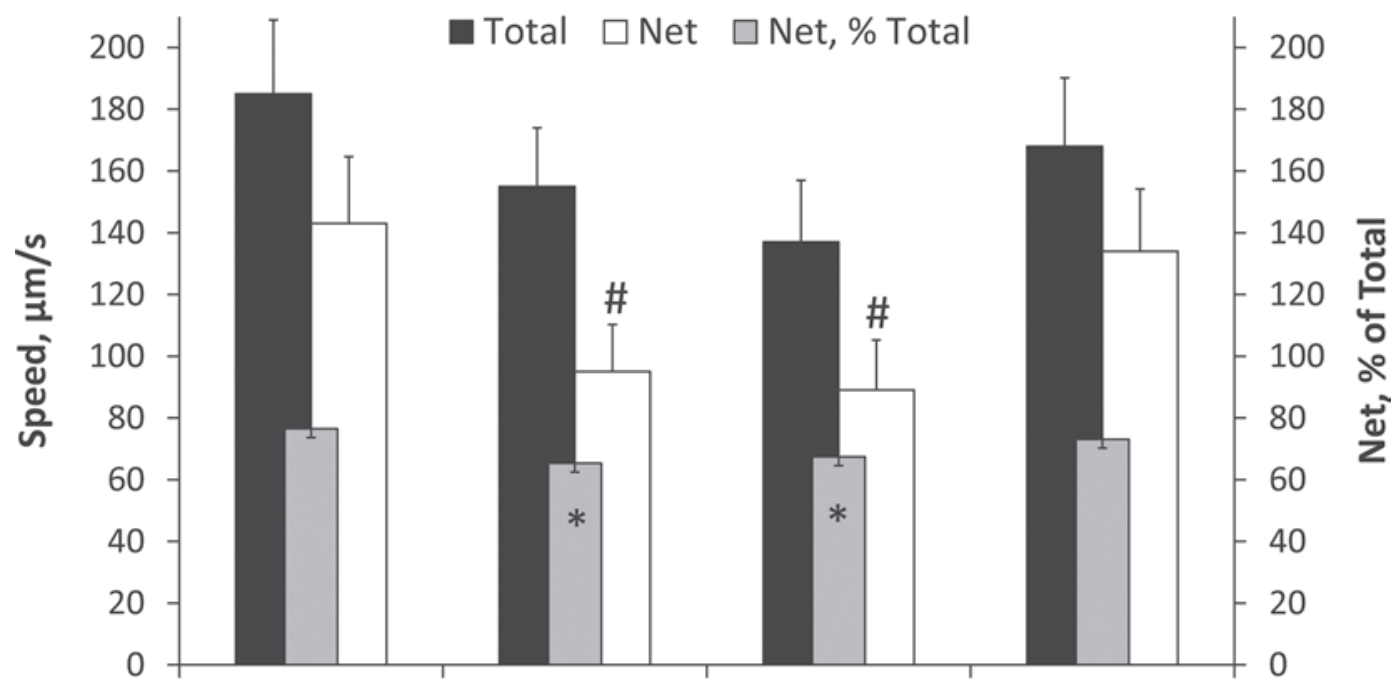

B) Isotrichidids

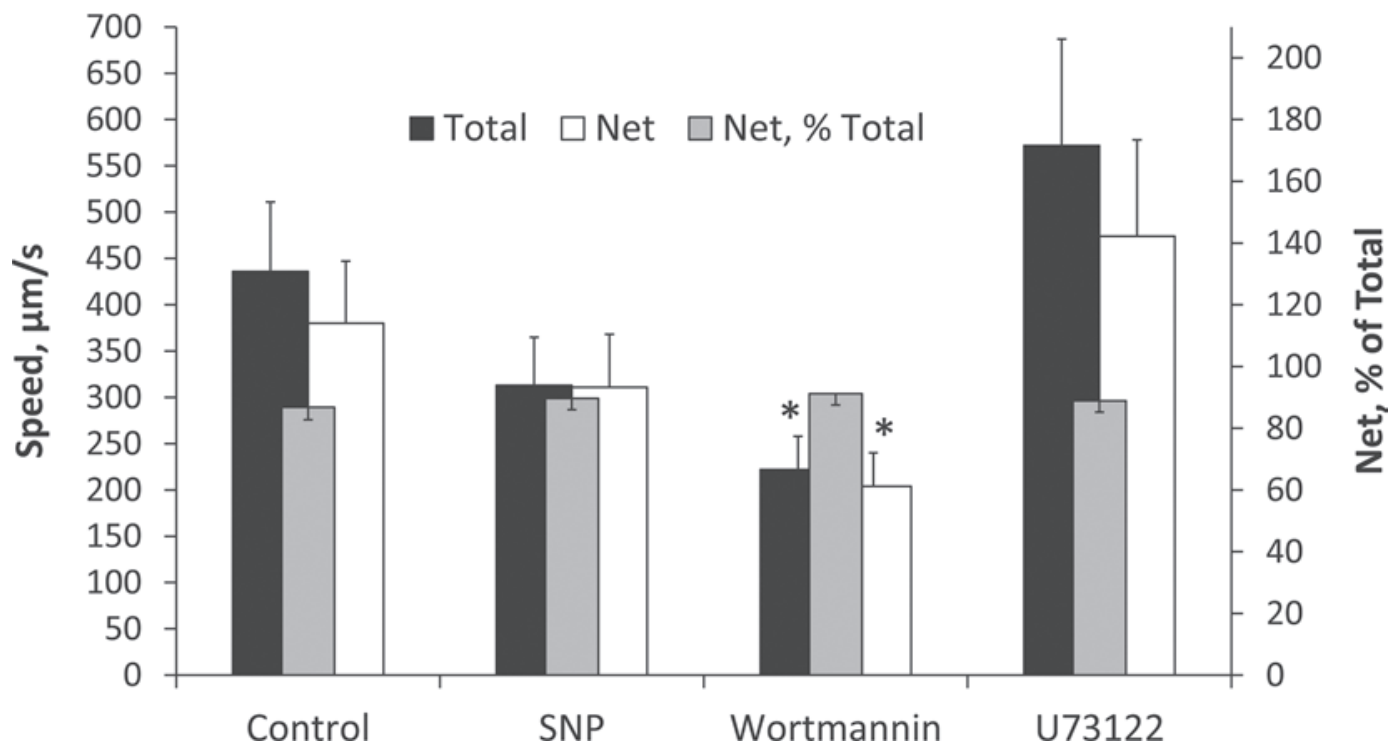

Figure 4. Effect on total (including turns) and net (excluding turns) speed after incubating ruminal fluid with solvent (control), sodium nitroprusside (Snp), wortmannin, or U73122 for $3 \mathrm{~h}$ as assessed for mixed entodiniomorphids (A) or isotrichids (B) in experiment 4 . Differences from the respective controls indicated by $*(P<0.05)$ or \# $(P<0.08)$.

\section{DISCUSSION}

\section{Kinetics of Bead Uptake as Influenced by Glucose and Feeding}

Our objectives were to optimize the usage of fluorescent beads to distinguish rate and extent of phagocytosis by En. caudatum, which is highly amylolytic, compared with Ep. caudatum, which is highly fibrolytic, when unfed or dosed sequentially with ground wheat and orchardgrass. We expected En. caudatum to ingest beads more rapidly than Ep. caudatum based on observations of bacterial uptake (Coleman and Laurie, 1977; Belanche et al., 2012).

The much greater asymptotic bead uptake with the increased dosage of beads (experiment 1; Figure 2) suggests that the frequency of contact with beads increases ingestion of those beads by En. caudatum. Compared with the unfed treatment, the fed treatment moderately stimulated rate of bead uptake by En. caudatum in experiment 1 . In contrast, in experiment 2 (Figure 3A), feeding the culture at the same time as 
bead dosage decreased rate of bead uptake by more than 5-fold. Because glucose only moderately increased asymptotic uptake for unfed En. caudatum cultures, it appears to have a minor role in feeding behavior (even though it is a chemoattractant to entodiniomorphids, Table 1). Thus, internal filling was probably different among experiments. When considering the effects of bead dosing rate and kinetics, results from both experiments support the notion that bacterial ingestion is inversely related to ingestion of particulate matter but can be particularly rapid for En. caudatum that are starved. For Ep. caudatum in experiment 2 (Figure $3 \mathrm{~B}$ ), both feeding and provision of glucose increased the rate of bead uptake but more moderately. Thus, bacterial ingestion by this species appears to be indirectly in response to feeding because bacteria would also be colonizing and degrading the same substrates.

Williams and Coleman (1992) explained that ingested starch limited internal capacity for the amount of bacteria ingested, but provision of glucose could help fuel the predation process. In an experiment using radiolabeled glucose, Coleman and Laurie (1974) demonstrated that an Ep. caudatum culture had faster absorption of free glucose than an En. caudatum culture. Of the relatively few entodiniomorphid species studied, glucose probably passes rapidly into the ectoplasm and polymerizes, whereas the entry of glucose into the endoplasm is slower (Williams and Coleman, 1992). Our culture of Ep. caudatum, but not all strains of this species (Dehority, 2010), visibly attacks fresh particulate matter right after feeding (it is highly fibrolytic), so glucose hydrolysis near the cilial motors should help fuel this feeding response.

Bacteria have long been known to be required for normal growth and function by ruminal protozoa. Live bacteria should increase the growth rate of ruminal protozoa compared with autoclaved bacteria (Fondevila and Dehority, 2001), whereas adsorption of bacterial extracts to ingested charcoal particles increased growth of Ophryoscolex (a large entodiniomorphid) in culture (Mah, 1964), documenting the importance of internalizing nutrients from bacteria, not necessarily exclusive to predation of intact bacteria. Williams and Coleman (1992) noted a trend that protozoa grown in vitro had 1.5- to 17.6-fold faster rates of bacterial uptake than those collected in vivo, so we chose to use cultures initially as a more responsive screening (experiments 1 and 2) but to follow up with mixed ruminal protozoa (experiment 3).

\section{Integration of Chemotaxis Results with Bead Uptake and Motility}

Experiment 3 used a chemotaxis assay (Diaz et al., 2014a) from which capillary tubes containing chemo- sensory compounds were open only at the bottom, close to where the fluorescent beads sedimented in the beakers, thereby assessing chemotaxis (Table 1) from the same entodiniomorphids from which beads were binned (Tables 3 and 4). After optimizing for $10^{8}$ beads $/ \mathrm{mL}$ (Figure 2), 20 min for chemotaxis also represented the time when bead uptake was near half of asymptotic bead uptake (Figures 2 and 3). Although experiment 4 is the first to our knowledge to measure speeds of ruminal protozoa (Figure 4), these values by isotrichids compare closely with those of the fully ciliated genus Tetrahymena (Leick et al., 1997) found in freshwater.

\section{Compounds with Expected Responses at the Exterior Surface of Protozoa}

Glucose, peptides, and GTP in capillary tubes were expected to elicit chemotactic and chemorepellent responses ostensibly mediated through external receptors. Insulin and genistein were expected to sensitize and desensitize chemosensory responsiveness, respectively, via receptors at the protozoal surface, although starved Tetrahymena might respond to internalized insulin (Csaba et al., 2008). All signal transduction was proposed to be integrated with dynamic $\mathrm{Ca}^{2+}$ currents coordinating cilial beating (Figure 1A).

As expected, glucose was a chemoattractant to both groups of protozoa (Tables 1 and 2) and was more intense for isotrichids (Diaz et al., 2014a). Similarly, peptides were consistent chemoattractants to entodiniomorphids in that study and our second study (Diaz et al., 2014b). Entodiniomorphids are more proteolytic and bacterivorous than the sugar-metabolizing isotrichids (Hristov and Jouany, 2005). In contrast to our first study (Diaz et al., 2014a) but consistent with our second (Diaz et al., 2014b), soy peptides were chemorepellent for isotrichids (Table 2), nearly completely reversing the chemoattraction to glucose. In the first study, there were minor differences whether the peptides were from soy, bacterial, or even protozoal origin. Protozoal protein could be a reservoir for proteolysis by either lysis or autophagy (Forsberg et al., 1984). Chemorepellence is important evolutionarily in free-swimming ciliates (Robinette et al., 2008), and GTP is a universal stress indicator of damaged cells (Bartholomew et al., 2008). Although GTP did not exacerbate chemorepellence to peptides in the current results, it did reverse isotrichid chemoattraction to glucose previously (Diaz et al., 2014b).

Insulin's partial recovery from wortmannin's inhibition of growth in our prior study, reputedly mediated through a receptor tyrosine kinase (Diaz et al., 2014b), was not related to chemotaxis or phagocytosis (proxied by bead uptake) in the present study. Insulin represents 
general peptide growth factors supporting growth or recovery from stress in Tetrahymena (Christensen et al., 2003). Because genistein (another projected ligand for a separate receptor tyrosine kinase) also had no consistent role for entodiniomorphids in this or our prior study (Diaz et al., 2014b), a potential mechanism for insulin remains uncertain in ruminal protozoa.

\section{Sodium Nitroprusside Stimulation of Circular Swimming}

When dissolved in DMSO, Snp was assumed to penetrate through protozoal membranes and generate nitric oxide for subsequent activation of the protein kinase G-mediated turning behavior required for chemotaxis (Leick and Chen, 2004). The addition of Snp to beakers did not affect random swimming into saline capillary tubes, whereas Snp increased chemotaxis toward glucose (Table 1), which is supported by our prior results (Diaz et al., 2014b). Because net (but not total) swimming speed was decreased (Figure 4A), Snp likely stimulated directional turning needed for chemoattraction toward a glucose gradient but also would explain less net swimming distance for cells in the beakers to reach the opening of the capillary tubes with only saline (Diaz et al., 2014b). In contrast to that in entodiniomorphids, the lack of Snp response for chemotaxis (Table 2) or motility (Figure 4B) by isotrichids supports their deemphasized need for circular swimming behavior for substrate acquisition.

\section{U73122 and Wortmannin Inhibition of Phosphoinositide Signaling Pathways}

Both U73122 and wortmannin were projected to pass through protozoal membranes for internal mechanisms (Figure 1B). Contrary to our hypothesis, the PLC inhibitor U73122 did not reverse Snp stimulation of chemotaxis toward glucose by entodiniomorphids or isotrichids. However, U73122 increased random swimming by entodiniomorphids into capillary tubes containing either Sal or Glc but not peptides (Table 1) and increased swimming speed by $30 \%$ without achieving significance (Figure 4). The motility model (Figure 1A) can be mediated through swimming speed (toward attractants or away from repellents) by the percentage of T. thermophila cells displaying those behaviors (Lampert et al., 2011). Thus, U73122 might have increased the percentage of entodiniomorphids exhibiting such behavior, which would increase random swimming into Sal tubes (Table 1) but also increase variability (and decrease statistical power) in Figure 4.

Addition of wortmannin to beakers, regardless of combination with other compounds, decreased random swimming by entodiniomorphids into Sal capillary tubes but increased chemotactic swimming to capillary tubes filled with Glc (Table 1), as verified by similar results in the companion study (Diaz et al., 2014b) and by the motility assay (Figure 4A). Combining those responses with the dramatic decrease in uptake of inert beads by those entodiniomorphids (Table 3) would suggest wortmannin inhibition at earlier stages of phagocytosis. Wortmannin inhibited actin polymerization to initiate phagocytosis in T. pyriformis (Kovacs and Pallinger, 2003), although subsequent disruption of digestive vacuole trafficking (Leondaritis et al., 2005) could also exacerbate energy depletion or perhaps decrease bead excretion.

In contrast to that in entodiniomorphids, addition of wortmannin to beakers decreased chemotaxis toward Glc in capillary tubes by isotrichids (Table 2) and decreased both total and net swimming speeds (Figure 4B). Our different responses can be unified in that both wortmannin and U73122 interrupted $\mathrm{Ca}^{2+}$ gradients used in chemotaxis in T. pyriformis, but apparently through different mechanisms (Nam et al., 2009). Leondaritis et al. (2011) discussed the role of a predominant isoform of PLC in Tetrahymena to rate-limit the concentrations of phosphatidylinositol-4,5-phosphate, which is substrate for both PI3K and PLC (Figure 1B). Thus, wortmannin should shift inositide balance away from inositides needed for phagosomal maturation and cell proliferation for entodiniomorphids but might disrupt $\mathrm{Ca}^{2+}$ homeostasis more critically for the fully ciliated and more motile isotrichids.

\section{Divergent Roles of Chemotaxis and Phagocytosis in Entodiniomorphid and Isotrichid Ecology}

Some strains of Ep. caudatum are particularly active at shredding fresh feed or remaining in fixed locations while feeding on fresh forage particles (Dehority, 2010), and these and other entodiniomorphids only momentarily attach to particles (Dehority, 1998). Thus, entodiniomorphids primarily use cilia for swimming in the fluid while remaining adjacent to the degradable particulate matter and for ingestion. Entodiniomorphids consume more and larger particles than isotrichids (explained previously). Motility results from Snp and wortmannin and the latter compound's role in bead uptake support the integration of phagocytosis with swimming behavior (Figure 5A). Results also help document our original expectations that entodiniomorphids successfully sustain growth rates high enough to maintain their populations while passing with the particulate phase of ruminal digesta (Firkins et al., 2007).

In contrast to the entodiniomorphids, isotrichidsincluding the very large Isotricha species - consume 


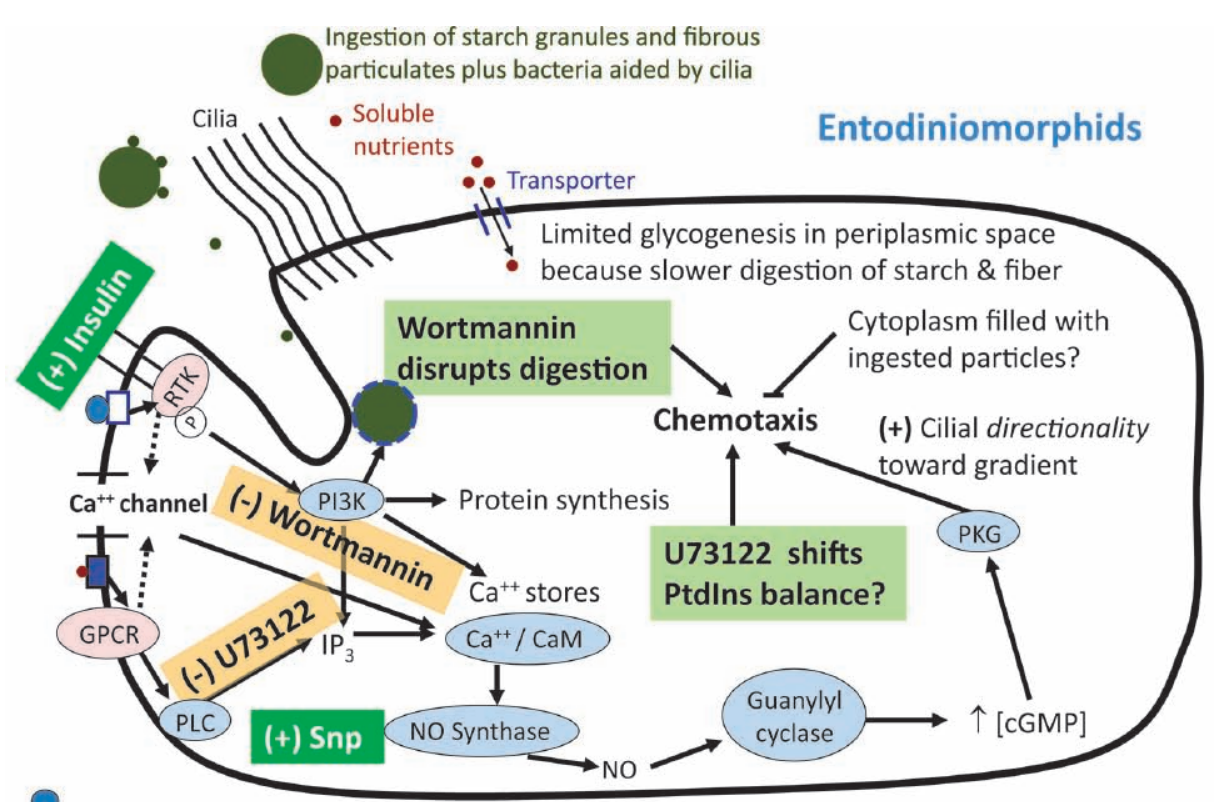

Peptide-bound receptor

Sugar-bound receptor

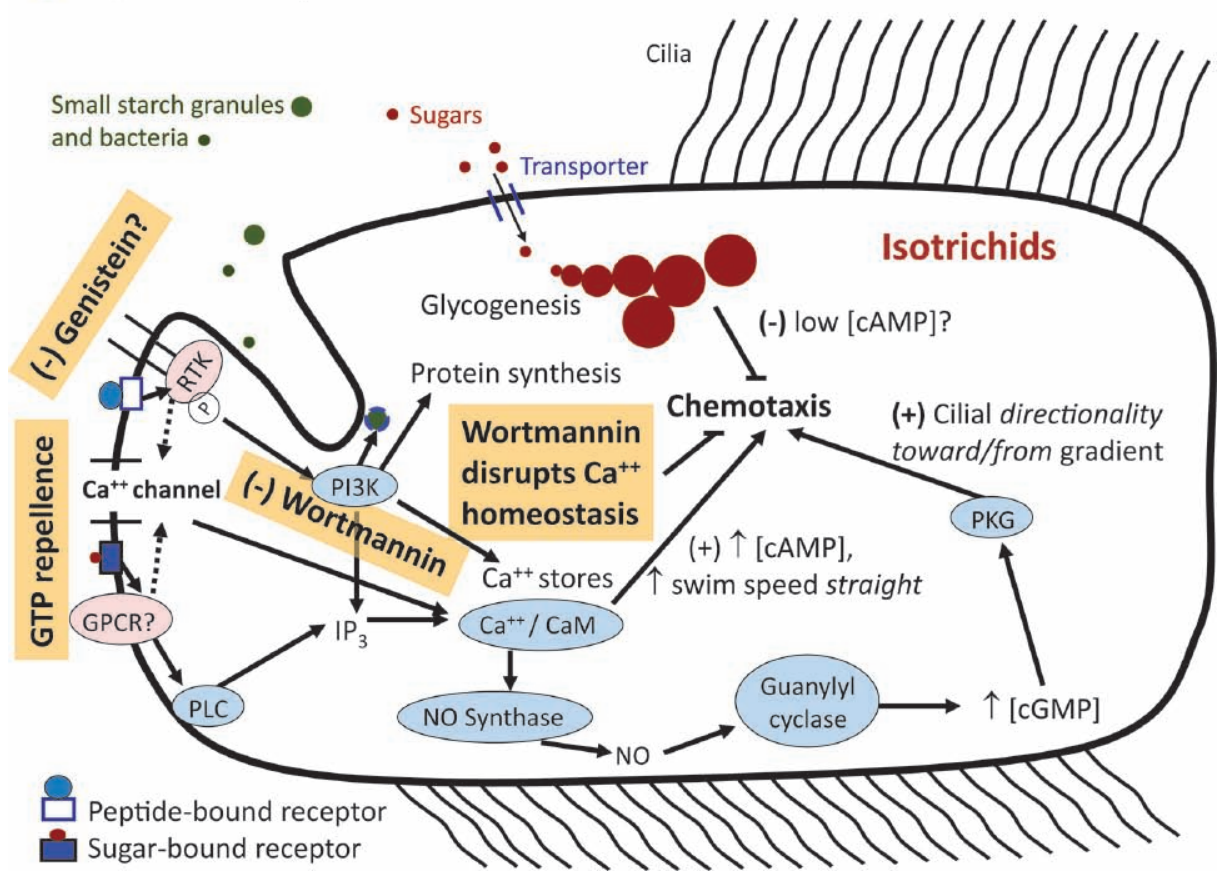

Figure 5. Schematic models derived from Figure 1 but supported by findings from the current and companion studies (Diaz et al., 2014a,b) with ruminal protozoa. Entodiniomorphids (top) are chemoattracted to both peptides and glucose. Wortmannin inhibited growth, but insulin helped recover growth. Wortmannin and sodium nitroprusside (Snp) increased chemotaxis to glucose, which was verified by the motility assay (experiment 4). Wortmannin also decreased bead uptake, which should disrupt digestion and deplete cellular energy status to sensitize entodiniomorphids for enhanced chemotaxis to glucose. Because wortmannin did not alter chemotaxis to peptides, AA are assumed to be used more for protein synthesis than for energy generation. U73122 also has the potential to sensitize chemotaxis toward glucose but did not affect motility, so a potential role in phosphatide balance was labeled with a question mark. Because the process of simultaneously feeding with addition of beads decreased the rate of bead uptake by entodiniomorphids, filled cytoplasmic volume is proposed to decrease chemotaxis or cilia-mediated positioning of feed particles toward the vestibulum. Isotrichids (bottom) are highly chemoattracted to glucose and other sugars for rapid and extensive synthesis of glycogen-like storage polysaccharide. Once an isotrichid is replete with storage polysaccharide, a decreased cyclic AMP (cAMP) concentration is proposed to decrease motility. Because wortmannin had the opposite effect for isotrichids as for entodiniomorphids, wortmannin more likely disrupts $\mathrm{Ca}^{2+}$-homeostasis of isotrichids with the surrounding ruminal fluid. In support, wortmannin decreased net swimming (and net, \% total) but not total swimming by entodiniomorphids but decreased both net and total swimming (not affecting net, \% of total) by isotrichids. Guanosine triphosphate (GTP) had no effect on peptide repellence by isotrichids but did blunt their chemotaxis toward glucose. Genistein repeatedly tended to decrease chemotaxis toward glucose by isotrichids, so a potential role is labeled with a question mark. 
only very small starch granules and use sugars as their primary substrate (Dehority, 2003), probably by evolutionarily adapting their vestibulum (mouth) and cilia (Paul et al., 1989). Thus, chemotaxis or chemorepellence by isotrichids appears to be mediated through swimming speed for distance (Figure 5B). In the genera Tetrahymena and Paramecium (also fully ciliated), chemoattraction in an aqueous environment involves turning toward, and swimming faster to, a compound but then also adapting to remain in the vicinity of those higher concentrations (Leick et al., 1997; Bell et al., 2007). Avoidance behavior also is mediated through variation in $\mathrm{Ca}^{2+}$ currents (Lampert et al., 2011).

Dehority and Tirabasso (1989) suggested that filled stores of reserve polysaccharide should signal isotrichids to stay in the ventral reticulorumen until reserve polysaccharide was depleted enough for those cells to resume migration dorsally. Sedimentation below the reticulo-omasal orifice is often provided as a mechanism to explain the slow growth rate of isotrichids, although generation times by isotrichids are not well known (Dehority, 2003). In contrast to the observation that isotrichids slowed their growth rate when they were highly filled with storage polysaccharide (Williams and Coleman, 1992), one could argue the opposite. That is, growth might be uncoupled by a limitation from some nutrient or other factor resulting from removal of that nutrient or factor from the rumen, thereby causing extensive glycogen filling. Routing glucose to excess storage polysaccharide is energetically inefficient in anaerobic microbes (Hackmann et al., 2013). Moreover, when provided excessive sugars in vitro, isotrichids become filled with glycogen to the point of bursting (Hall, 2011). However, batch culture would heighten the availability of glucose and resultant synthesis of storage polysaccharide and lessen the opportunity for repellence away from lysing conditions. The blunting of chemotaxis to glucose by GTP (Diaz et al., 2014b) and the increasing chemorepellence to peptides in that and the current study would presumably reduce lysis from uncontrolled sugar consumption in vivo compared with observations in vitro. Chemorepellence also might help direct protozoa from and through a dense, rapidly degrading dorsal mat with limited mixing (Storm and Kristensen, 2010) to the ventral rumen, where particulates are less likely to occlude sedimenting isotrichids and lytic conditions are diminished.

\section{CONCLUSIONS}

We evaluated the dynamics of fluorescent bead uptake and motility assays for the first time and simultaneously assessed phagocytosis with chemosensory behavior by ruminal protozoa that were preincubated with combinations of eukaryotic inhibitors or activators. Results from companion reports and the current report were accumulated into separate proposed models that coordinate the differential motility and membrane trafficking by entodiniomorphids and isotrichids, thereby helping to explain their differential ecology in the rumen.

\section{ACKNOWLEDGMENTS}

Research was supported by state and federal funds appropriated to the Ohio Agricultural Research and Development Center, The Ohio State University. Research funds were provided by the USDA National Research Initiative Grant 2008-35206-18847. This paper is manuscript number $22 / 13 \mathrm{AS}$. The authors appreciate the valuable discussions with our colleagues Timothy Hackmann (University of Florida, Gainesville), Mark Morrison (University of Queensland, Brisbane, Australia), and Zhongtang Yu (The Ohio State University, Columbus). This manuscript is dedicated to Burk Dehority (The Ohio State University, Wooster), whose curiosity, knowledge, and scientific experience have been invaluable over the years.

\section{REFERENCES}

Abe, M., T. Iriki, N. Tobe, and H. Shibui. 1981. Sequestration of holotrich protozoa in the reticulo-rumen of cattle. Appl. Environ. Microbiol. 41:758-765.

Bartholomew, J., J. Reichart, R. Mundy, J. Rechtenwald, S. Keyser, M. Riddle, and H. Kuruvilla. 2008. GTP avoidance in Tetrahymena thermophila requires tyrosine kinase activity intracellular calcium, NOS, and guanylyl cyclase. Purinergic Signal. 4:171-181.

Belanche, A., G. de la Fuente, J. M. Moorby, and C. J. Newbold. 2012. Bacterial protein degradation by different rumen protozoal groups. J. Anim. Sci. 90:4495-4504.

Bell, W. E., R. R. Preston, J. Yano, and J. L. Van Houten. 2007. Genetic dissection of attractant-induced conductances in Paramecium. J. Exp. Biol. 210:357-365.

Christensen, S. T., C. F. Guerra, A. Awan, D. N. Wheatley, and P. Satir. 2003. Insulin receptor-like proteins in Tetrahymena thermophila ciliary membranes. Curr. Biol. 13:R50-R52.

Coleman, G. S., and J. I. Laurie. 1974. The metabolism of starch, glucose, amino acids, purines, pyrimidines and bacteria by three Epidinium spp. isolated from the rumen. J. Gen. Microbiol. $85: 244-256$.

Coleman, G. S., and J. I. Laurie. 1977. The metabolism of starch, glucose, amino acids, purines, pyrimidines and bacteria by the rumen ciliate Polyplastron multivesiculatum. J. Gen. Microbiol. 98:29-37.

Csaba, G., P. Kovacs, and E. Pallinger. 2008. Comparison of the insulin binding, uptake and endogenous insulin content in longand short-term starvation in Tetrahymena. Cell Biochem. Funct. 26:64-69.

Dehority, B. A. 1998. Generation times of Epidinium caudatum and Entodinium caudatum, determined in vitro by transferring at various time intervals. J. Anim. Sci. 76:1189-1196.

Dehority, B. A. 2003. Rumen Microbiology. Nottingham University Press, Nottingham, UK.

Dehority, B. A. 2010. Physiological characteristics of several rumen protozoa grown in vitro with observations on within and among species variation. Eur. J. Protistol. 46:271-279. 
Dehority, B. A., and P. A. Tirabasso. 1989. Factors affecting the migration and sequestration of rumen protozoa in the family Isotrichidae. J. Gen. Microbiol. 135:539-548.

Desjardins, M., and G. Griffiths. 2003. Phagocytosis: Latex leads the way. Curr. Opin. Cell Biol. 15:498-503.

Dias, N., A. L. Amaral, E. C. Ferreira, and N. Lima. 2003. Automated image analysis to improve bead ingestion toxicity test counts in the protozoan Tetrahymena pyriformis. Lett. Appl. Microbiol. $37: 230-233$.

Diaz, H. L., S. K. R. Karnati, M. A. Lyons, B. A. Dehority, and J. L. Firkins. 2014a. Chemotaxis toward carbohydrates and peptides by mixed ruminal protozoa when fed, fasted, or incubated with polyunsaturated fatty acids. J. Dairy Sci. 97:2231-2243. 10.3168/ jds.2013-7428

Diaz, H. L., J. R. Knapp, S. K. R. Karnati, B. A. Dehority, and J. L. Firkins. 2014b. Effects of wortmannin, sodium nitroprusside, insulin, genistein, and guanosine triphosphate on chemotaxis and cell growth of Entodinium caudatum, Epidinium caudatum, and mixed ruminal protozoa. J. Dairy Sci. 97:2244-2253. 10.3168/jds.20137429.

Firkins, J. L., Z. Yu, and M. Morrison. 2007. Ruminal nitrogen metabolism: Perspectives for integration of microbiology and nutrition for dairy. J. Dairy Sci. 90(E. Suppl.):E1-E16.

Fondevila, M., and B. A. Dehority. 2001. In vitro growth and starch digestion by Entodinium exiguum as influenced by the presence or absence of live bacteria. J. Anim. Sci. 79:2465-2471.

Forsberg, C. W., L. K. A. Lovelock, L. Krumholz, and J. B. BuchananSmith. 1984. Protease activities of rumen protozoa. Appl. Environ. Microbiol. 47:101-110.

Gonda, K., K. Oami, and M. Takahashi. 2007. Centrin controls the activity of the ciliary reversal-coupled voltage-gated $\mathrm{Ca}^{2+}$ channels $\mathrm{Ca}^{2+}$-dependently. Biochem. Biophys. Res. Commun. 362:170176 .

Hackmann, T. J., L. E. Diese, and J. L. Firkins. 2013. Quantifying the response of mixed rumen microbes to excess carbohydrate. Appl. Environ. Microbiol. 79:3786-3795.

Hall, M. B. 2011. Isotrichid protozoa influence conversion of glucose to glycogen and other microbial products. J. Dairy Sci. 94:45894602.

Harfoot, C. G., and G. P. Hazlewood. 1997. Lipid metabolism in the rumen. Pages 382-426 in The Rumen Microbial Ecosystem. P. N. Hobson and C. S. Stewart, ed. Blackie Academic \& Professional, New York, NY.

Hennessey, T. M., and T. J. Lampert. 2012. Behavioral bioassays and their uses in Tetrahymena. Methods Cell Biol. 109:393-410.

Hristov, A. N., and J.-P. Jouany. 2005. Factors affecting the efficiency of nitrogen utilization in the rumen. Pages 117-166 in Nitrogen and Phosphorus Nutrition of Cattle and Environment. A. N. Hristov and E. Pfeffer, ed. CAB International, Wallingford, UK.

Karnati, S. K. R., J. T. Sylvester, S. M. Noftsger, Z. Yu, N. R. StPierre, and J. L. Firkins. 2007. Assessment of ruminal bacterial populations and protozoal generation time in cows fed different methionine sources. J. Dairy Sci. 90:798-809.

Kovacs, P., and E. Pallinger. 2003. Phosphatidylinositol 3-kinase-like activity in Tetrahymena: Effects of wortmannin and LY 294002. Acta Protozool. 42:277-285.

Lampert, T. J., K. D. Coleman, and T. M. Hennessey. 2011. Chemoattraction to lysophosphatidic acid does not require a change in membrane potential in Tetrahymena thermophila. Cell Biol. Int. $35: 519-528$.
Leick, V., and F. Chen. 2004. Chemosensory behaviour and ciliary cyclic GMP-dependent protein kinase in Tetrahymena thermophila. Eur. J. Protistol. 40:303-312.

Leick, V., C. Iversen, K. Kemp, and S. T. Christensen. 1997. Protein kinase inhibitors abolish adaptive cell behavior in Tetrahymena. Acta Protozool. 36:249-260.

Leondaritis, G., T. Sarri, I. Dafnis, A. Efstathiou, and D. Galanopoulou. 2011. Biochemical and genetic evidence for the presence of multiple phosphatidylinositol- and phosphatidylinositol 4,5-bisphosphate-specific phospholipases $\mathrm{C}$ in Tetrahymena. Eukaryot. Cell 10:412-422.

Leondaritis, G., A. Tiedtke, and D. Galanopoulou. 2005. D-3 phosphoinositides of the ciliate Tetrahymena: Characterization and study of their regulatory role in lysosomal enzyme secretion. Biochim. Biophys. Acta 1745:330-341.

Mah, R. A. 1964. Factors influencing the in vitro culture of the rumen ciliate Ophryoscolex purkynei Stein. J. Protozool. 11:546-552.

Moya, C. E., and R. S. Jacobs. 2006. Pseudopterosin A inhibits phagocytosis and alters intracellular calcium turnover in a pertussis toxin sensitive site in Tetrahymena thermophila. Comp. Biochem. Physiol. C Toxicol. Pharmacol. 143:436-443.

Nam, S.-W., S.-T. Kim, K.-M. Lee, S. H. Kim, S. Kou, J. Lim, H Hwang, M. K. Joo, B. Jeong, S. H. Yoo, and S. Park. 2009. NMethyl-D-aspartate receptor-mediated chemotaxis and $\mathrm{Ca}^{2+}$ signaling in Tetrahymena pyriformis. Protist 160:331-342.

Nusblat, A. D., L. J. Bright, and A. P. Turkewitz. 2012. Conservation and innovation in Tetrahymena membrane traffic: Proteins, lipids, and compartments. Methods Cell Biol. 109:141-175.

Parry, J. D., K. Heaton, J. Drinkall, and H. L. J. Jones. 2001. Feasibility of using GFP-expressing Escherichia coli, coupled with fluorimetry, to determine protozoan ingestion rates. FEMS Microbiol. Ecol. 35:11-17.

Paul, R. G., R. D. Butler, and A. G. Williams. 1989. Ultrastructure of the rumen ciliate Dasytricha ruminantium. Eur. J. Protistol. 24:205-215.

Robinette, E. D., K. T. Gulley, K. J. Cassity, E. E. King, A. J. Nielsen, C. L. Rozelle, T. J. Warren, J. M. Morrow, and H. G. Kuruvilla. 2008. A comparison of the polycation receptors of Paramecium tetraurelia and Tetrahymena thermophila. J. Eukaryot. Microbiol. 55:86-90.

Storm, A. C., and N. B. Kristensen. 2010. Effects of forage particle size and dry matter content of a total mixed ration on intraruminal equilibration and net portal flux of volatile fatty acids in lactating dairy cows. J. Dairy Sci. 93:4223-4238.

Sylvester, J. T., S. K. R. Karnati, B. A. Dehority, M. Morrison, G. L. Smith, N. R. St-Pierre, and J. L. Firkins. 2009. Rumen protozoa decrease generation time and adjust $18 \mathrm{~S}$ ribosomal DNA copies to adapt to decreased transfer interval, starvation, and monensin. J. Dairy Sci. 92:256-269.

Valeyev, N. V., P. Heslop-Harrison, I. Postlethwaite, A. N. Gizatullina, N. V. Kotov, and D. G. Bates. 2009. Crosstalk between G-protein and $\mathrm{Ca}^{2+}$ pathways switches intracellular cAMP levels. Mol. Biosyst. 5:43-51.

Williams, A. G., and G. S. Coleman. 1992. The Rumen Protozoa. Springer-Verlag, New York, NY.

Williams, A. G., A. B. Ellis, and G. S. Coleman. 1986. Subcellular distribution of polysaccharide depolymerase and glycoside hydrolase enzymes in rumen ciliate protozoa. Curr. Microbiol. 13:139-147. 